\title{
The Economics of Setting Auditing Standards*
}

\author{
Minlei Ye \\ University of Toronto \\ Dan A. Simunic \\ University of British Columbia \\ Ralph Winter \\ University of British Columbia
}

April 2010

\begin{abstract}
This paper develops a theory of the negotiating positions, or preferences over auditing standards, of the interest groups that may set such standards or negotiate changes in standards. We represent auditing standards by two properties: toughness and vagueness (or lack of precision). Our model predicts that auditors and investors would consider both toughness and vagueness to influence or set auditing standards (e.g., preference over vagueness depends on the level of toughness.) Since the market is composed with auditors with different wealth and different investment projects, the optimal level of standards would be different for these parties. Therefore, in general, auditing standards with a certain level of vagueness is preferred. By analyzing economic incentives in the process of setting auditing standards, we help explain how the standards have developed into their current form.

\footnotetext{
${ }^{*}$ We greatly appreciate the advice from Kin Lo, Hugh Neary, and Sandra Chamberlain. An earlier
} version of the paper benefited from comments by Florin Sabac and Paul Fischer. We also wish to thank Paul Newman, Bill Kinney, Volker Laux, Gordon Richardson, Ping Zhang, Gilles Hilary, Jeroen Suijs, Robert Knechel, the anonymous referee for CAPANA conference, and seminar participants at the University of British Columbia, University of Toronto, University of Texas at Austin, HEC Paris, Tilburg University, and City University of Hong Kong.
\end{abstract}




\section{Introduction}

Auditing standards evolve as an outcome of regulations among affected interest groups, as well as changes in the relative influence of these groups. This paper is based on the premise that a theory of different groups' preferences over auditing standards can shed light on the setting and evolution of the standards. Prior to 2002, the American Institute of Certified Public Accountants (AICPA) set Generally Accepted Auditing Standards (GAAS) as the standards for audits conducted for both public and private companies in the United States (U.S.). The AICPA is the national professional organization for Certified Public Accountants (CPAs), so this meant that the auditing profession was able to set its own auditing standards. The Sarbanes-Oxley Act of 2002 (SOX), however, created the Public Company Accounting Oversight Board (PCAOB) to oversee the auditors of public companies, and authorized the PCAOB to establish auditing and related professional practice standards for publicly held companies. At the time, an article in BusinessWeek proposed that the PCAOB take over audit standards and write tougher rules that protect the public investors, not CPAs. ${ }^{1}$ SEC commissioner Paul S. Atkins claimed that, "The PCAOB was created because of deep failings in the U.S. accounting profession's ability to regulate itself." ${ }^{2}$ However, the U.S. situation is not unique as auditing standards in most countries are set by professional organizations of auditors. Moreover, in recent years, auditing standard-setting boards around the world have been trying to improve the clarity of auditing standards by, for example, adding objectives for each standard and making structural changes to improve the readability of the standards. ${ }^{3}$

\footnotetext{
${ }^{1}$ Mike McNamee, Accounting Watchdog-or lapdog? Here's how you'll know. BusinessWeek, Nov. 11, 2002.

${ }^{2}$ Speech by SEC Commissioner: The Sarbanes-Oxley Act of 2002: Goals, Content, and Status of Implementation, February 5, 2003.

${ }^{3}$ The goals of these 'clarity projects' include addressing concerns over length and complexity of standards, and making standards easier to read, understand and implement. Interestingly, these projects cause auditing standards to be more principle-based or less detailed, which implies that the resulting standards are vaguer, as defined in this paper.
} 
These facts raise interesting questions. From an economic point of view, was it appropriate to transfer the authority for establishing auditing standards for publicly held companies from the AICPA to the PCAOB in the U.S., and why are different auditing standard boards implementing clarity projects? This paper analyzes different parties' (namely investors and audit firms of varying sizes) preferences concerning the properties of auditing standards to provide implications for the standard setting. Among other things, we find that investors generally have the same preference for auditing standards as auditors, which implies that investors will not necessarily be better off if they can set the standards directly. Moreover, auditing standards do not have to be perfectly precise in order to be efficient. Vagueness (which may be characterized as adopting principles-based standards) can add value to the efficiency of auditing standards and can be preferred by standard-setters, in some circumstances.

In the design of auditing standards, as in the design of any law, regulation or rule, two dimensions must be considered. The stringency or toughness of the requirements imposed by the standard on auditors is of course central. But the degree of generality or vagueness in the language specifying the standard is also critical. No standard will be written so precisely that the language eliminates all discretion in auditing activities and on the other hand a standard that is expressed in language that is too broad has less meaning and can generate uncertainty in the auditing setting. Therefore, this study focuses on two properties of auditing standards: toughness and vagueness (or lack of precision). We interpret the average level of audit work required by the standards as the "toughness" or "stringency" of auditing standards. In contrast, the magnitude of judgment variation concerning possible audit effort levels that could be considered as in compliance with the auditing standards represents the "vagueness" or "imprecision" of auditing standards. Thus, standards with less ambiguity concerning a "due diligent" audit effort level are defined as being more precise. Also, as noted earlier, rules-based standards are likely to be more precise than principles-based standards.

We analyze how the properties of auditing standards affect auditors' behavior and com- 
pare different parties' preferences for the toughness and vagueness of auditing standards. Based on Dye [1993], we present a model of the audit market relating auditors' legal liability to auditing standards and in which the perceived audit quality is linked to an auditor's wealth. Our innovation is the introduction of uncertainty or vagueness in auditing standards. The vagueness of auditing standards affects the perceived probability of compliance, thereby influencing the auditor's expected legal liability, which in turn influences audit effort. This approach allows us to analyze the impact of vagueness on auditor's effort, as well as the auditor's and investors' attitudes towards vagueness. To our knowledge, this is the first study that represents auditing standards in terms of their two essential properties: toughness and vagueness. ${ }^{4}$

Turning to results, when auditing standards can be made precise, we find, small (less wealthy) auditors who have "less to lose" from litigation prefer less tough rules than large (wealthy) auditors, when auditor wealth is observable. Investors have the same preferences as auditors that they will hire. This is true because a group of investors who are interested in undertaking an investment project will hire an auditor with wealth greater than a certain cutoff point, which is a function of the amount of investment. Hence a unique set of auditing standards can be optimal for both the investor and the auditor, while the variation in investments allows for the existence of small auditors.

Regarding the preference for vagueness, an auditor prefers precise auditing standards if the toughness can be set at the optimal (wealth-maximizing) level. If the toughness can not be set optimally, then the auditor prefers vague auditing standards - whether the toughness is too high or too low. When the standards are too tough (e.g., higher than optimal level), vagueness allows the auditor to exert a lower level of effort without facing penalties with certainty. That is, the auditor can exploit the vagueness of standards and exercise professional judgment to avoid performing unnecessary procedures. When the standards are too weak, a level of uncertainty in the standards can help the auditor commit to a higher

\footnotetext{
${ }^{4}$ To make the model more realistic, we also consider not perfectly predictable auditor responses to vagueness. This variation as shown in the last subsection does not affect our implications.
} 
level of effort because his wealth is at risk. Investors have the same preferences regarding vagueness as the auditor in the weak-standards scenario, since vagueness induces the auditor to undertake the desired level of audit effort, from the investors' point of view. Investors also have the same preferences regarding vagueness as the auditor in the case of excessively tough standards since vagueness reduces the expected costs of the audit. In the real world, an auditor has clients with projects requiring different amount of investments, so there is not one unique level of effort that is optimal for all the clients, which implies the toughness can not be set optimally. Therefore, auditing standards with a certain level of vagueness is preferred. Additionally, different auditors have heterogeneous wealth, the optimal level of standards would be different for each party. Our theory predicts that vague standards are preferred. This is consistent with the fact that the standards have been vague.

Some of the costs and benefits of vagueness have been recognized in general. For example, a greater level of precision allows greater predictability in the standard on the part of both auditors and investors - and greater predictability on the part of purchasers of the professional services as to the level and quality of service that will be supplied. On the other hand, as a matter of positive rather than normative theory, an excessively precise theory may be difficult to enact when various parties who are affected, and who influence the setting of the standard, have sharply different preferences. A proposed vague standard may be central to gathering enough political support to become an adopted standard while precise standards may never garner enough support to become adopted. In contrast, our paper proposes another interesting and perhaps equally important theory regarding the preferences. As stated above, a perfectly predictable standard has zero variance and would be preferred by both parties, providing that toughness is at the level that generates maximum combined expected wealth for the parties. Surprisingly, however, both parties prefer vague standards conditional upon a suboptimal level of toughness.

To summarize, this paper contributes to the literature by investigating standard setters' economic incentives to develop auditing standards with certain properties and to negotiate 
changes in auditing standards. We believe the research is timely given the recent transfer of authority over auditing standards for public companies from the AICPA to the PCAOB in the U.S., and the world-wide trend of improving the clarity of auditing standards. Our research thereby helps to explain why the standards have developed into their current form.

Section 2 positions the paper in the context of the existing literature. Section 3 provides the definition and mathematical representation of toughness and vagueness of auditing standards. Section 4 presents the model, and Section 5 demonstrates the players' objectives. Section 6 and 7 present the model's predictions. Sections 8 concludes.

\section{Prior Research}

While several papers have examined auditors' reactions to variations in either toughness or vagueness of auditing standards, to our knowledge, no research has considered the question of how the properties of auditing standards - namely both toughness and vagueness - would be chosen by standard-setters (i.e., auditors and investors).

Studies in the law and economics literature analyze the impact of uncertain liability rules on parties' behavior. Calfee and Craswell [1984] find that uncertainty about the application of legal standards can give parties economic incentives to "overcomply" or to "undercomply", that is, to modify their behavior to a greater or lesser extent than a legal rule requires. Kolstad et al. [1990] show that where there is uncertainty, there are inefficiencies associated with the exclusive use of negligence liability and that ex ante regulation can correct the inefficiencies.

Most studies in the current audit literature assume liability rules are precise or certain, as expressed in Zhang [2007], Narayanan [1994], Dye [1993], Melumad and Thoman [1990],

Nelson et al. [1988], and others. Dye [1993] and Zhang [2007] are closely related to our paper. Dye [1993] analyzes auditors' attitudes toward and responses to the level (toughness) of auditing standards. He shows that the average quality of audits may decline as auditing standards are raised. Moreover, auditors who intend to comply with the standards typically 
prefer higher standards than those who do not comply, when auditors' wealth levels are observable to outsiders; when auditors' wealth levels are not publicly observable, the reverse is true. Dye [1993] does not consider the interaction between legal liability regimes and auditing standards, nor the fact that auditing standards are inherently vague. The level of auditing standards is perfectly precise in Dye's model. Zhang [2007] finds that the public's expectations can induce an auditor to exert a higher level of effort. This result is similar to our finding that when the standards are too weak, vagueness can help an auditor commit to a higher level of effort since his wealth is at risk. While we construct the likelihood of an auditor being found liable based on the courts' interpretation of auditing standards, the probability of being found liable in Zhang [2007] is influenced by whether courts will use public expectations to make a decision.

Willekens et al. [1996] and Schwartz [1998] analyze the impact of uncertainty about auditor due care (negligence) on audit effort or quality, and the role of professional auditing standards in a setting of an uncertain legal environment. Willekens et al. [1996] argue that audit standards only affect auditor behavior if legal standards of care are unclear, and the audit standards help to clarify the legal standards. Schwartz [1998] finds that the commitment to perform according to auditing standards is not credible if the auditor legal liability regime is strict liability or negligence-based liability with a clear legal due care standard. She shows that under a negligence-based liability regime with vague due care, the commitment to perform according to auditing standards can improve audit effort. The auditing standards themselves, however, are always assumed to be perfectly precise in Willekens et al. and in Schwartz's theory.

The vagueness (or lack of precision) of auditing standards can vary across countries and through time. Vagueness affects auditors' legal liability since it influences courts' judgment as to the auditors' due diligence. However, little existing research analyzes how the vagueness of auditing standards affects auditors' effort, and how the vagueness of auditing standards is determined by standard-setters. Willekens and Simunic [2007] and Ewert [1999] are the 
exceptions. Willekens and Simunic [2007] model the impact on audit effort of changes in the vagueness of auditing standards and conclude that decreasing the precision of the standards initially induces an auditor to produce higher audit quality by exerting more effort, but beyond a certain critical value, decreasing precision leads to decreasing effort and auditors gambling that they may or may not be deemed to have violated the standards. When vagueness exceeds a second critical value, auditors exert no effort at all. The auditing standards are exogenously determined in Willekens and Simunic [2007]. That is, the authors do not model the standard setting process, and they do not consider the interaction of the toughness and vagueness of auditing standards. In this paper, we analyze the optimal standards for different standard setters (auditors vs. investors). Since the level of toughness of auditing standards affects the auditors' and investors' preferences towards the vagueness of auditing standards, we consider the interaction of toughness and vagueness when standard setters choose the properties of auditing standards. We find that heterogeneity in auditor wealth is essential in our theory, while Willekens and Simunic assume homogeneous auditor wealth. Ewert [1999] argues that vague auditing standards can outperform precise standards by inducing higher audit quality, higher quality of financial statements, lower expected legal costs, and lower direct as well as total audit costs than precise standards. However, reasonable extensions of his model seem to lead to the possibility of (non-degenerate) equilibria with pure auditor strategies, which do not support his main argument (Breuer [1999]). We characterize the equilibria with auditor pure strategies, and consider "the probability that the court judges auditing level $a$ as a sub-standard" when the standards are vague. Ewert's finding is consistent with one part of our results in that, for some levels of toughness and vagueness, vaguer standards induce higher audit effort and lower costs than precise ones. We further find that under other conditions, audit effort is lower when the standards are vaguer. Our analysis shows that auditors' preference over vagueness depends on the level of toughness. When toughness is optimal for auditors, they weakly prefer precise standards. When toughness is non-optimal, the auditors prefer vaguer standards. 
Finally, Patterson and Smith [2003] analyze the effect of materiality uncertainty on the auditor's evaluation of audit evidence and a manager's choice of earnings overstatement. They find that when the expected cost of accepting financial statements that are materially misstated is relatively large, an increase in uncertainty over materiality results in a more conservative auditor evaluation of the audit evidence and a decrease in the amount of intentional overstatement. Otherwise, the reverse is true. Our representation of uncertainty is similar to their construct of uncertainty (mean-variance approach). But our focus is on the uncertainty of audit effort required by auditing standards while their focus is on uncertainty of materiality. Our focus allows us to analyze the impact of auditing standards on auditors and identify the economic forces driving the evolution of auditing standards. We find that the mean of the distribution affects the impact of variance on auditors and their preference over variance, while Patterson and Smith's model provides evidence on the impact of uncertainty on auditors and managers judgments, conditional on the trade-off between cost of audit failure and cost of further audit procedures. ${ }^{5}$

To summarize, while existing research has considered certain aspects of how auditors, investors, and managers may behave given a set of auditing standards, this paper explores the process of setting such standards by different interest groups. Moreover, we jointly consider the two basic properties of auditing standards - their toughness and vagueness, with an objective of synthesizing some critical ideas within the current literature and advancing our understanding of the economic forces underlying the standard setting process.

\footnotetext{
${ }^{5}$ Moreover, Patterson and Smith assume the materiality follows a normal distribution instead of a uniform distribution. Use of the uniform distribution allows us to find closed-form solutions, while the normal distribution does not, and later analysis will show our results are not sensitive to this assumption.
} 


\section{Definitions and Mathematical Representations}

\subsection{DEFINITIONS}

The first property of auditing standards under consideration is toughness or stringency. This concept is important in analyzing auditing standards because auditing standards determine the amount of work auditors must undertake. We define the toughness of auditing standards as:

Definition D1: The toughness of auditing standards is the average level of audit effort required by the standards.

The second property of auditing standards analyzed is vagueness. With perhaps the exception of certain mathematical concepts and categories, virtually all concepts or categories used in everyday life are vague, and therefore it would follow that auditing standards are characterized by vagueness as well. We analyze vagueness concerning the level of audit effort that can be considered as in compliance with auditing standards. Vagueness is simply the uncertainty of this audit effort. The probability of non-compliance can be reduced by increasing audit effort, which is costly to auditors. Audit effort in practice may include collecting and evaluating audit evidence, and the auditor conferring with the manager when the two parties disagree with each other. We associate a higher level of audit effort with higher audit quality. ${ }^{6}$

Formally, we define the vagueness of auditing standards as the following:

Definition D2: The vagueness of auditing standards is the uncertainty of audit effort levels that could be considered by different parties as "in compliance" with the auditing standards.

\footnotetext{
${ }^{6}$ It is important to note that our focus is on the vagueness of auditing standards rather than the vagueness of accounting standards. The vagueness of accounting standards is related to the representational faithfulness of different transactions (Caplan and Kirschenheiter [2004], Schipper [2003], Vincent et al. [2003], Nelson [2003], Dye and Sridhar [2008]). We do not consider the impact of accounting vagueness on auditors. Rather, we analyze vagueness in relation to the level of audit effort that can be considered as in compliance with auditing standards.
} 


\subsection{MATHEMATICAL REPRESENTATIONS}

We use the mean-variance approach to represent the properties of auditing standards. This approach assumes that the level of audit effort required by expressed standards is a random variable "s", which has density $g(s)$ (or distribution $G(s)$ ) with mean $m$ and variance $\delta^{2}$. A "tougher" standard is an increase in the mean of the distribution. A "vaguer" standard is an increase in the uncertainty in $G$, i.e., in the sense of second-order stochastic (SS) dominance. In other words, if standard No. $1(s 1)$ SS-dominates standard No. $2(s 2)$ at the same mean, then $s 1$ is less vague than $s 2$. Under the mean-variance approach, the variance of the distribution represents the vagueness of auditing standards and the mean represents the toughness of auditing standards. Note that when the standards are perfectly precise, the level of audit effort required by expressed standards, $s$, equals the toughness $m$.

To illustrate the impacts of the properties of auditing standards on auditors, we analyze the simplest and most intuitive distribution: the standard $s$ is distributed uniformly. Suppose $s$ is distributed uniformly within the support of lower bound $s_{l}$ and upper bound $s_{h}$, then the mean $m=\frac{s_{l}+s_{h}}{2}$ and the variance $\delta^{2}=\frac{\left(s_{h}-s_{l}\right)^{2}}{12}$. The lower bound can be denoted by $m-\sqrt{3} \delta$, and the upper bound is $m+\sqrt{3} \delta$. The toughness of the standards is represented by $m$. Thus, the vagueness of the standards is represented by the variance $\delta^{2}$ (or the standard deviation $\delta$ ).

The mean-variance approach is reasonable since real-world auditing standards are uncertain. For example, paragraph 6 of PCAOB Auditing Standard No. 3 (A.S.3), "Audit Documentation", states that "the auditor must document the procedures performed, evidence obtained, and conclusions reached with respect to relevant financial statement assertions. Audit documentation must clearly demonstrate that the work was in fact performed....". This standard requires auditors to document the procedures, evidence, and conclusions, but the extent of the documentation required is uncertain. A.S.3 paragraph 7 states that, "In determining the nature and extent of the documentation for a financial statement assertion, 
the auditor should consider the following factors: (1)...(5). Application of these factors determines whether the nature and extent of audit documentation is adequate." This paragraph reduces the uncertainty associated with the documentation procedures. The toughness is the number of factors and vagueness is the range of possible factors an auditor should consider.

Overall, the advantage of the mean-variance approach is that we can analyze how vagueness affects audit effort while holding the toughness constant, and how standard setters would choose the vagueness given the toughness. We will employ this approach to analyze how different parties will set or influence auditing standards.

\section{The Model}

This is a single-period model with two sets of risk neutral players (prospective investors in a firm and an auditor). ${ }^{7}$ A firm seeks to raise capital in the form of equity to start a project. $^{8}$ With probability $\beta$ this project is a good project and generates a cash flow of $B$ (which belongs to the prospective investors), whereas with probability $1-\beta$ it is a bad project and yields zero return in the future. This project needs $\$ I$ upfront investment from potential investors. ${ }^{9}$ The above information is known to the investors, but they do not know the true type of the project when they make the investment decision. Assume that $\beta(B-I)+(1-\beta)(0-I)>0$, so that the investors would invest in the project without knowing the project's type, but would not make the investment if they know that the project is bad. $^{10}$

The firm manager issues a report, which we interpret to be in the form of financial

\footnotetext{
${ }^{7}$ Risk aversion would not significantly affect our results.

${ }^{8}$ Our analysis is not restricted to new issuers. As is common in the accounting, finance, and entrepreneurial literature, it is standard to represent a firm as a "project". Changing the model description to "one generation of investors is selling its firms to another generation of investors for life cycle reasons" as Dye [1993], Dye [1995], Dye [2002] will not affect the analysis.

${ }^{9}$ We will show the impact of variation of the investment amount $I$ in a later analysis.

${ }^{10}$ This assumption is to ensure that the investors will invest when the auditor reports a good signal even if ex ante they know there is possibly a Type-II error, and that they will not invest when the auditor reports a bad signal.
} 
statements, which disclose his estimate of the project. ${ }^{11}$ The investors can hire an auditor (there is only one auditor in the market) to issue an audit report with respect to the financial statements in order to obtain an independent assessment of the project. ${ }^{12}$

The auditor exerts effort $a \in[0,1]$ in the audit process and obtains a binary signal about the project's type (i.e., signal $\in\{\operatorname{good}, \mathrm{bad}\}$ ). The level of audit effort is not publicly observable when the auditor's report is issued: it becomes observable when the auditor is sued. The auditor might not be able to detect material misstatements due to audit technology limitations or inadequate audit effort. As is common in the literature, the relation between the audit report and the true type of project is as follows:

$$
\operatorname{Pr}(g \mid \text { good }, a)=1 \text { and } \operatorname{Pr}(b \mid b a d, a)=a,
$$

where $g$ denotes the auditor's signal that the project is good, and $b$ denotes the bad signal (financial statements have material misstatements). We use $a$ to denote the level of effort as well as the probability of detecting the bad project conditional on a bad project and effort $a$. This assumption indicates that the auditor will make no mistakes when there is no misstatement in the financial reports (i.e., there is no Type-I error), and that he may fail to detect misstatements depending on his audit effort (i.e., there may be a Type-II error). ${ }^{13}$ We assume the auditor is independent and reports the observed signal truthfully.

Audit failure is the situation in which the project is bad but the auditor issues a "good" report; in other words, he does not detect material misstatements in the financial statements. The investors will make an inappropriate investment decision in this case and incur a loss of

\footnotetext{
${ }^{11}$ To keep the model simple, we do not consider the manager's disclosure incentives, his decision concerning internal control, or litigation against the manager. It is assumed that the manager would always claim that the project type is good. The auditor may be viewed as obtaining information about the veracity of the manager's assertions about the project type. The auditor would provide either a qualified or unqualified opinion. This assumption is similar to the one in Laux and Newman [2009]. A strategic manager assumption will affect the level of optimal effort, but not our finding on the auditor and investors preferences towards the standards.

${ }^{12}$ We will first assume there is only one auditor/audit firm in the market, which can be regarded as an aggregation of many auditors with the same wealth, and then analyze how the results will change if there are many audit firms with different wealth.

${ }^{13}$ We assume no Type-I error since we consider only auditor liability resulting from the failure to detect misstatements. Relaxing this assumption increases audit effort, but will not affect the key results.
} 
$\$ I$. The probability of audit failure conditional on the project being bad is given by $1-a .{ }^{14}$ The investors will sue the auditor if an audit failure occurs and the probability of the auditor being found liable is positive. Once the auditor is found liable, he is required to pay the entire loss $I$ or his wealth, whichever is smaller. ${ }^{15}$

The innovative element in our model is an assumption that in addition to the above events, there is one more event that occurs in the first stage of the game: the standardsetting board (either an organization representing investors' interests or the professional organization for auditors) sets the auditing standards. The auditing standards affect the auditor's perceived liability and thereby his effort choice.

To analyze the relation between auditing standards and auditors' behavior, we need to discuss the link between auditing standards and auditors' legal liability, since the impact of auditing standards on auditors is affected by the types of legal regimes. Schwartz [1998] suggests that the interaction between auditing standards and auditors' liability occurs only when legal due care for auditors is not clearly defined, since this ambiguity induces courts to resort to auditing standards for guidance on due care.

Under a hypothetical strict liability regime, the auditor is liable for losses resulting from investor reliance on materially misstated financial reports, independent of the amount of audit effort exerted. Thus, the probability of being held liable equals "one" at all effort levels if the auditor fails to detect material misstatements. Auditing standards will increase audit effort because greater effort implies a higher probability of detecting misstatements, but will not help to reduce the probability of being found liable by courts once audit failure (i.e. a failure to detect a material misstatement) occurs.

Under a negligence-based liability regime, the auditor is liable for the losses incurred by investors only if he failed to exercise due care. Due care is the minimum effort level that the auditor is required to exercise in order to avoid liability. When due care is not specified in

\footnotetext{
${ }^{14}$ Assuming the probability of audit failure to be $\exp (-a)$ as in Newman et al. [2005] will not change the analyses.

${ }^{15}$ Changing the liability payment from $I$ to any amount less than $I$ will not affect the analyses.
} 
the law (i.e., when legal due care is vague), the courts resort to auditing standards in order to determine the due care level and auditor negligence. Currently in the U.S. and elsewhere, the legal liability regime for auditors is negligence-based and the due care level expected from an auditor is not defined by law. Hence, the professional auditing standards affect auditors' liability, and therefore affect auditors' behavior under a negligence-based liability regime with vague due care. We assume auditors' liability is under a negligence-based liability regime with due care defined by auditing standards to simplify the analysis. ${ }^{16}$

Recall that we assume a single audit firm ("the auditor") in the main analysis. If the auditor can control the setting of auditing standards, then in equilibrium he will choose the properties of auditing standards strategically to maximize his expected profit. Moreover, since the auditor's incentive to work is limited by his wealth and in the actual audit market auditors have heterogeneous wealth levels, we will analyze how the auditor's wealth affects his preferences towards the properties of auditing standards. In reality, people can judge whether the auditor is relatively wealthy, although they may not know his exact wealth. Here, we simply assume the auditor's wealth to be observable. This completes the description of the basic model and the key assumptions.

\section{The Players' Objectives}

The investors' and auditor's objectives and the sequence of events after considering the effect of legal liability regimes and auditing standards are summarized in Figure 1. Investors' objectives are derived as follows. When an audit is conducted, the auditor can detect a bad project with probability $a$. The investors will not invest if they know it is a bad project, thus saving $\$ I$. The probability of the project being bad is $1-\beta$. Hence, the gross benefit the investors can obtain by hiring an auditor is $\$(1-\beta) a I$. Moreover, these potential investors may recover some money if there is an audit failure and they sue the auditor. They also need to pay an audit fee to hire the auditor. Therefore, the net benefit or value of hiring an

\footnotetext{
${ }^{16}$ Further analysis shows our results hold for a large class of liability rules.
} 
auditor includes three components: (1) gross benefit $\$(1-\beta) a I$; $(2)$ the expected liability payment investors can obtain from the auditor; and (3) the audit fee. The sum of the first two components (i.e., $(1-\beta) a I+E L(a))$ is the benefit of the audit. The audit fee is the cost of hiring an auditor. Note that we do not consider the case when investors need to incur a litigation cost in this model, since the litigation cost affects investors' suing decisions, and it will result in the auditor choosing sub-standard effort in equilibrium, which is not the focus of our paper. The formal analysis incorporating investors' suing decisions is available from the authors upon request. Formally, the net benefit that investors obtain through an audit is calculated as follows:

$$
V(a)=(1-\beta) a I+E L(a)-F
$$

The expected liability the investors can obtain from the auditor who exerts effort $a$ is given by:

$$
E L(a)=(1-\beta)(1-a)(1-P(a)) \min [W, I]
$$

where $1-\beta$ is the probability of the project being bad; the probability of audit failure is $1-a ; P(a)$ is the probability of compliance (i.e., the probability that given an effort $a$ the auditor will be found in compliance, $\operatorname{or} \operatorname{Prob}(s \leq a)) ; 1-P(a)$ is the probability of being found liable, $I$ represents the investment losses, and $W$ is the auditor's wealth. Due to limited liability, the auditor's liability will be either $W$ if $W \leq I$ or $I$ if $I<W{ }^{17}$ Under a negligence-based liability regime with due care defined by auditing standards, $P(a)$ is determined by the auditing standards. Therefore, the investors' objective is to induce the auditor to exert the level of effort that maximizes the value of the audit, as indicated by equation $5 . .1$.

The auditor's objective is to choose an effort level to maximize his profit, which is the audit fee, denoted by $F$, minus the total expected cost, which is the sum of the costs of the effort expended on the audit plus the auditor's expected liability payments to the investors.

\footnotetext{
${ }^{17}$ The audit fee is only a small part of the auditor's final wealth.
} 
Formally, the auditor's objective is:

$$
a=\underset{[0,1]}{\operatorname{argmax}} F-c(a)-E L(a),
$$

where $c(a)$ is the auditor's resource cost of producing an audit effort level $a$. It is convex and increasing in $a$ (i.e., $c^{\prime}(a)>0$ and $c^{\prime \prime}(a)>0$ ). To derive a closed-form solution, we assume $c(a)=\frac{1}{2} c a^{2}$, where $c^{\prime}(a)=c a>0$ and $c^{\prime \prime}(a)=c>0 .{ }^{18}$ The expected liability $E L(a)$ is as defined in Equation 5..2.

\subsection{FIRST-BEST SOLUTION}

The first-best contract can be struck if the level of audit effort is observable and contractible. We will solve for the first-best optimal level of effort and the audit fee in this section. This first-best result serves as a benchmark for the later analyses when the level of effort is not observable.

The investors' problem is:

$$
\begin{array}{cl}
\max _{F, a} & (1-\beta) a I-F \\
\text { s.t. } & F-c(a) \geq 0
\end{array}
$$

where $c(a)=\frac{1}{2} c a^{2}$. Solving the above problem, we obtain the first-best level of effort $c^{\prime}(a)=$ $(1-\beta) I$ (marginal cost equals marginal benefit). Under the functional form assumption $c(a)=\frac{1}{2} c a^{2}$, the first-best level of effort equals

$$
a^{*}=(1-\beta) I / c \text {. }
$$

Note that $a$ also represents the probability of detecting the bad project. To ensure an interior solution, we assume $(1-\beta) I / c \leq 0$, that is, $c \geq(1-\beta) I$.

\footnotetext{
${ }^{18}$ Assuming this quadratic form simplifies the exposition and is commonly used in the auditing literature. The results presented in the remainder of this paper are robust to other specifications of (positively sloped) convex cost functions.
} 


\subsection{AUDIT EFFORT IS UNOBSERVABLE}

In reality, the level of audit effort is not observable to investors. The auditor's choice of effort is subject to an incentive constraint. As commonly employed in the recent theoretical literature on problems of auditor liability, we assume contingent audit fees are prohibited. This is consistent with the codes of professional ethics of most countries, including the U.S.. In equilibrium, the auditor will choose a level of effort that minimizes the total audit costs. The investors anticipate the auditor's strategy and set the audit fee equal to the auditor's reservation payoff so that he is indifferent to accepting or declining the audit engagement. Note that a monopoly auditor can set the audit fee and earn economic rents, but the equilibrium level of effort is the same whoever can earn rents.

One might argue that the auditor can maximize his profit by (a) exerting NO effort and (b) always reporting that the project is bad, since the auditor will neither incur liability nor effort costs. This scenario is avoided, since we assume that the auditor will be punished severely if he reports "bad" and the signal is revealed later to be good. This assumption is reasonable because the auditor is able to observe good projects with certainty given effort $a$ (i.e., $\operatorname{Pr}(g \mid$ good, $a)=1)$.

As discussed in Section 4., the model is derived under a negligence-based liability regime with due care defined by auditing standards. To analyze how the vagueness of auditing standards affects the auditor's effort choice, we first demonstrate the auditor's behavior assuming the auditing standards are perfectly precise.

\section{Perfectly Precise Auditing Standards}

As a benchmark, we consider first the case where auditing standards can be perfectly precise, and analyze the impact of toughness in auditing standards on auditor effort. When perfectly precise auditing standards define due care, the auditor can reduce the probability of being held liable to "zero" if his effort is greater than or equal to the level specified in the standards. 
In this case, his total cost will be limited to the resource cost. If he does not comply with the auditing standards, then he will definitely be found liable if audit failure occurs, and his total cost will be the sum of resource cost and expected liability payment (i.e., $T C\left(a_{s}\right)=\frac{1}{2} c a_{s}^{2}+(1-\beta)\left(1-a_{s}\right) \min [W, I]$ where $\left.a_{s}=\frac{(1-\beta) \min [W, I]}{c}\right)$. Thus, there is a range of $s$ within which the auditor will comply. Recall that when the standards are perfectly precise, the level of audit effort required by expressed standards, $s$, equals the toughness $m$.

Let $\bar{s}$ be the highest standard with which the auditor will comply. As illustrated in Figure 2, if the standard equals $s^{\prime}$, then the auditor's cost of complying is $c\left(s^{\prime}\right)$ which is less than $T C\left(a_{s}\right)$. Moreover, if the standard equals $s^{\prime \prime}$, then the auditor's cost of complying $c\left(s^{\prime \prime}\right)$ is greater than $T C\left(a_{s}\right)$. Therefore, the highest standard with which the audit will comply is such that the auditor is indifferent between compliance and noncompliance (i.e., $\left.c(\bar{s})=T C\left(a_{s}\right)\right)$.

Therefore, the second-best results under the assumption of precise standards are $a^{\dagger}=s$ if $s \leq \bar{s}$ and $a^{\dagger}=a_{s}$ if $s>\bar{s}$, where $\bar{s}=\sqrt{\frac{2}{c}(1-\beta) \min [W, I]-\frac{(1-\beta)^{2}(\min [W, I])^{2}}{c^{2}}}$ and $a_{s}=$ $\frac{(1-\beta) \min [W, I]}{c}$. The auditor will comply with the auditing standards as long as the toughness of auditing standards is less than the critical value $\bar{s}$. Otherwise, the auditor will not comply with the auditing standards. Note that $\bar{s}$ varies with auditor wealth.

These results are consistent with Schwartz [1998]'s finding that auditing standards in a vague negligence regime help auditors commit to a higher level of effort than under a strict liability regime. The difference between our findings is that we further develop the conditions under which an auditor will comply with the standards. Moreover, representing standards in toughness and vagueness allows us to distinguish the impact of these two factors on auditors. In the following section, we will show the impact of vagueness on auditors.

\section{Vague Auditing Standards}

In this section, we analyze the impact of vagueness in auditing standards on the auditor's effort choice. This analysis has important implications for standard setters. It is also the 
foundation of the analysis concerning standard setters' economic incentives to choose the vagueness of auditing standards.

Again, the auditor chooses a level of effort $a$ to minimize total audit costs, which equals the audit fee. The key here is the probability of compliance $P(a)$. In this case, the $P(a)$ equals one if audit effort $a$ is greater than or equal to the upper bound of the distribution $m+\sqrt{3} \delta$, equals zero if $a<m-\sqrt{s} \delta$, and equals $\frac{a-m+\sqrt{3} \delta}{2 \sqrt{3} \delta}$ if $m-\sqrt{s} \delta \leq a<m+\sqrt{3} \delta$. Correspondingly, the auditor's effort choice includes $m+\sqrt{3} \delta, a_{s}$, and $a_{v}$, where $a_{s}=\frac{(1-\beta) \min [W, I]}{c}$ and

$$
a_{v}=\frac{(1-\beta) \min [W, I](1+\sqrt{3} \delta+m)}{2 \sqrt{3} \delta c+2(1-\beta) \min [W, I]},
$$

decreasing in $\delta$ (i.e., $\frac{\partial a_{v}}{\partial \delta}<0$ ). The detailed proof can be found in the Appendix equation 5 .

Figure 3 illustrates the auditor's effort choice (i.e., $m+\sqrt{3} \delta$, or $a_{v}$, or $a_{s}$ ) as a function of $m$ and $\delta$. Recall $m$ is the mean and $\delta$ is the variance of the distribution. The grey (dash dot dotted) line is the indifference curve where $m+\sqrt{3} \delta$ is equal to $a_{v}$. The red line (dash dotted) provides the values of $m$ and $\delta$ for which the auditor is indifferent in choosing $m+\sqrt{3} \delta$ or $a_{s}$. At the blue (dashed) line, the auditor is indifferent between $a_{s}$ and $a_{v}$. The line indicated by $1-\sqrt{3} \delta$ is the boundary for $m$, since $m+\sqrt{3} \delta$ should be less than or equal to one. The feasible region, which is below $1-\sqrt{3} \delta$, is partitioned into three sets by the grey, red, and blue lines. When $m$ and $\delta$ fall into region A, the auditor chooses his effort equal to $m+\sqrt{3} \delta$. When the toughness and vagueness are in region $\mathrm{B}$, the auditor will choose $a_{v}$ to be his effort level. When $m$ and $\delta$ is in the upper corner, region $\mathrm{C}$, the auditor will choose $a_{s}$.

To illustrate the auditor's effort reaction towards increased vagueness at a given value of $m$, we choose a particular $m$ and draw a figure illustrating the auditor's effort choice as a function of $\delta$. Suppose $m$ is quite high, for example, $m=0.81$ as indicated by the dotted line. We can see that as $\delta$ increases, an auditor first chooses effort equal to $m+\sqrt{3} \delta$; then $a_{v}$; then $a_{s}$; and then $a_{v}$ once again. Figure 4 illustrates this case. The auditor's effort will increase with the vagueness of auditing standards when the equilibrium level of effort is $m+\sqrt{3} \delta$, and will decrease with the vagueness if the equilibrium level of effort is $a_{v}$. If $a^{\dagger}=a_{s}$, then the vagueness of auditing standards will not affect the auditor's effort. 
When $m$ is fixed at values other than 0.81 in the above example, auditor's effort choice as a function of $\delta$ will change accordingly. If $m$ is fixed at a very high value $(m \in(\bar{s}=$ $\left.\left.\sqrt{2 a_{s}-a_{s}^{2}}, 1\right]\right)$, the auditor will not comply with the standards and choose $a_{s}$ whatever $\delta$ is. If $m$ is fixed at a moderately high value $\left(m \in\left(\bar{s}-\frac{(1-\beta) \min (W, I)(1-\bar{s})}{2 c \bar{s}}, \bar{s}\right]\right)$, the auditor will choose effort equal to $m+\sqrt{3} \delta$ and then $a_{s}$.

Define $m^{\dagger}$ as the minimum value of $m$ such that the auditor will choose effort equal to $a_{s}$. If $m$ is between $m^{\dagger}$ and $\bar{s}-\frac{(1-\beta) \min (W, I)(1-\bar{s})}{2 c \bar{s}}$, then the auditor first chooses effort equal to $m+\sqrt{3} \delta$; then $a_{v}$; then $a_{s}$; and then $a_{v}$ once again as illustrated in Figure 4 . For the vast majority of values of $m$ (e.g., $m<m^{\dagger}$ ), the auditor's effort will be $m+\sqrt{3} \delta$ and then $a_{v}$ as vagueness increases, suggesting that the auditor will initially increase and then decrease his effort.

Thus, varying the vagueness of auditing standards can change the level of audit effort in unexpected ways. An increase in the vagueness of auditing standards can decrease or increase audit effort. When the toughness is below the cutoff point $m^{\dagger}$ and the vagueness is very low, the auditor will attempt to comply with the upper bound to avoid liability. As the vagueness increases, however, his effort increases. But after the vagueness passes a critical point, the auditor will choose an effort level between the two bounds, and the level of effort decreases as vagueness increases.

Lemma 1 summarizes the findings formally. The proof can be found in Appendix.

Lemma 1. Given a standard with toughness $m$ less than $m^{\dagger}$, the auditor's effort initially increases with increasing vagueness, but after the vagueness passes a critical point, the auditor's effort decreases with vagueness.

Note that $m^{\dagger}$ is quite large, so it is generally true that auditor's effort increases and then decreases as the vagueness increases.

To this point, we have shown how the auditor's effort varies with the toughness and vagueness of the auditing standards. The next question is how the different standard setters would choose these properties of auditing standards to maximize their payoffs in the 
equilibrium. We analyze this question in the following sections.

\section{Toughness Preference Given Perfectly Precise Auditing Standards}

This section analyzes how different parties choose the toughness when the auditing standards are perfectly precise. This is a benchmark for studying the choice of vagueness of auditing standards. We investigate the levels of toughness the auditor and investors would choose under a negligence-based liability regime with due care defined by perfectly precise auditing standards. In order to get an understanding of the negotiations and interest group pressures to change auditing rules, we investigate the optimal standards preferred by each group. The courts determine auditors' liability based on the liability rules and auditing standards.

\subsection{AUDITOR'S PREFERENCE}

In this section, we analyze how the auditor will set the toughness of auditing standards if the standards can be set with perfect precision. This is the case of self-regulation. The auditor's objective for given standards would be to minimize his total cost if audit effort were his only choice. However, when he can choose the toughness of auditing standards, his objective becomes maximizing his total profit since the audit fee generally increases with the toughness of auditing standards because audit effort increases with the toughness as long as the toughness is below a critical value. The auditor can use the auditing standards as a device to commit to a level of effort. Since audit effort is unobservable, the auditor with low wealth can not credibly commit to the optimal level of effort that he would like to choose. He has an incentive not to comply because the cost of noncompliance will be lower than that of compliance.

Therefore, in equilibrium the auditor chooses the auditing standards in view of the audit fee and the audit effort to which he would like to commit. The central idea behind the auditor's choice of auditing standards is to convey a level of credibility in relation to the 
quality of service that he will provide. The investors will hire the auditor if their expected payoff is greater than the reservation payoff.

Assuming that auditor wealth is observable to investors, we find that an auditor with high wealth will set the toughness equal to the first-best level of effort (i.e., $(1-\beta) I / c)$ and an auditor with less wealth will set the toughness equal to the highest possible auditing standards to which his wealth allows him to commit (i.e., $(1-\beta) W / c+\epsilon$ ), which is less than $(1-\beta) I / c$ but higher than the noncompliance effort (i.e., $(1-\beta) W / c)$. Proposition 1 summarizes the argument. The proof can be found in Appendix.

Proposition 1. Given other parameter of the model, there exists a wealth level $W^{*}$ such that an auditor with wealth greater than $W^{*}$ will set the level of toughness equal to the first-best level of effort (i.e., $(1-\beta) I / c)$; An auditor with wealth less than $W^{*}$ will choose a lower toughness, but this toughness is increasing in auditor wealth. ${ }^{19}$

This proposition is consistent with Dye [1993]'s finding that auditors who intend to comply with the standards typically prefer higher standards than those who do not comply, when auditors' wealth levels are observable to outsiders. We further find the conditions under which an auditor will comply with higher standards.

\subsection{INVESTORS' PREFERENCE}

Given the assumption that there is one auditor with any wealth in the market, the auditor and investors have the same preferences related to the toughness, since they prefer the same optimal level of effort. An auditor with wealth greater than or equal to $W^{*}$ can commit to a standard requiring the first-best level of effort, since if he doesn't exert the first-best effort, his wealth will be used to pay off the liability owed to the investors. An auditor with small wealth can not commit to the first-best level of effort, since his wealth is not large enough to pay all the damages, and hence it is less costly for him to exert sub-standard effort (lower

${ }^{19}$ The wealth cutoff point $W^{*}$ is equal to $\frac{1-\sqrt{1-(1-\beta)^{2} I^{2} / c^{2}}}{(1-\beta) / c}$. 
than first-best). He is better off when the standard is at a level that he can commit to, rather than a high standard with which he can not comply. The investors can conjecture the auditor's behavior after observing his wealth, and set the standard to be the first-best if the auditor has large wealth, or the highest standard to which the auditor can commit if he has smaller wealth. As discussed in the previous sub-section, an auditor with large wealth will set the toughness equal to the first-best level of effort, and an auditor with small wealth will set the toughness equal to the highest possible auditing standards to which his wealth allows him to commit, which is less than the first-best. Therefore, contrary to the conventional wisdom that investors prefer tougher standards than auditors, we find that the investors have the same preference for toughness as the auditor. Formally, Proposition 2 summarizes the findings, and is based on the assumption that the standards are precise and there is one auditor in the market or many auditors with the same wealth. The proof can be found in the Appendix.

Proposition 2. The investors have the same preference for toughness as the auditor when the standards are precise and there is one auditor (or many auditors with the same amount of wealth) in the market.

\subsection{MULTIPLE AUDITORS WITH HETEROGENEOUS WEALTH AND MUL- TIPLE PROJECTS WITH DIFFERENT INVESTMENTS}

In this subsection we analyze whether Proposition 2 is sensitive to the assumption of one auditor and one group of investors in the market, and discuss the impact of multiple auditors with heterogeneous wealth and multiple projects with different investments on our results. First, if the market has many auditors with different wealth levels and only one project (or many projects with the same level of investment), then the investors will hire a large auditor and have the same preference over toughness as the auditor. ${ }^{20}$ Second, if there are

\footnotetext{
${ }^{20}$ If there is a positive exogenous probability that the investors would choose a small auditor, the average auditing standards preferred by auditors as a group might be lower than the ones preferred by the investors.
} 
many auditors with the same wealth and many projects with different amounts of investment, then investors again have the same preferences as the auditors, and desired standards become contingent on the investment amount. For projects with $I$ greater than a cutoff value, the first-best level of effort can not be achieved and these investors prefer standards inducing the second-best level of effort. For projects with $I$ less than a cutoff value, investors prefer standards inducing the first-best level of effort. Auditors choose effort based on the standards contingent on $I$. Third, if there are many auditors with different wealth and multiple projects with different investments, then the investors choose auditors with wealth greater than the specific amount $I$ for the project, and have the same preference as the auditor. Since there are projects with different investment amounts, smaller auditors could obtain business from smaller projects, which can explain why there are small auditors in the market. Small investors have different preferences over toughness than large investors, and small auditors disagree with large auditors about the level of toughness. The overall toughness of auditing standards then becomes a negotiated amount among different auditors or investors, but investors and the chosen auditors have the same preference over toughness.

This result is consistent with the fact that auditing standards are generally set by professional organizations for auditors. It implies that investors will not necessarily be better off if they can set the standards.

\section{Vagueness Preference}

Accounting and auditing standards, or any standards or laws for that matter, are inherently vague, since such standards cannot anticipate every possible future event. There is always room for interpretation as required in each context (Lo [2007]). The vagueness of auditing standards varies across countries and within one country over time. Since, in the real world, the legal liability regime for auditors is negligence-based and there are no separate legal due care standards for auditors, courts often resort to auditing standards to determine auditor liability. The vagueness of auditing standards affects auditors' perceived expected liabilities 
and hence their effort choices. The standard setters would consider these factors when they set the standards. The conventional conjecture would be that the standard setters (auditors or investors) would set the standards precisely, since this prevents under-compliance and overcompliance. However, the following analysis shows that the vagueness of auditing standards can be a strategic choice. In this section we analyze how and why different parties choose the vagueness strategically.

\subsection{AUDITOR'S PREFERENCE}

We derive the auditor's preference regarding the vagueness of auditing standards by analyzing the auditor's objective. As in Section 6.1, the auditor's objective is maximizing total profit, but here auditing standards can be vague instead of perfectly precise. The auditor's problem is to choose both the toughness and vagueness, and a level of effort to maximize his total profit conditional on the constraints.

The auditor's effort reaction function of vagueness illustrated in Figure 4 indicates that there are many combinations of toughness $m$ and vagueness $\delta$ that can generate the desired level of effort: $a^{*}=(1-\beta) I / c$ for auditors with wealth greater than $W^{*}=\frac{1-\sqrt{1-(1-\beta)^{2} I^{2} / c^{2}}}{(1-\beta) / c}$, and $(1-\beta) W / c+\epsilon$ for auditors with wealth less than $W^{*}$.

Since the auditor would not be worse off by setting standards precisely, he weakly prefers precise auditing standards. This preference, however, is affected by the feasibility of setting the standards to be precise. Since auditing standards are inherently vague, it is natural to assume that there is a minimum attainable vagueness that exists in the standards. Thus, the vagueness that can be chosen by the auditor will vary with the minimum attainable vagueness that the auditor can actually set.

When the minimum attainable vagueness is very small, the auditor will set the toughness at the optimal level and the vagueness at the minimum attainable level. Moreover, since the auditor is the standard setter, he can also change the toughness as the minimum attainable vagueness increases. To maintain the optimal level of effort, he could simply adjust the 
toughness as the minimum attainable vagueness becomes larger. Therefore, the auditor can set the vagueness at the minimum attainable level and reduce the toughness as minimum attainable vagueness increases. On the other hand, the auditor could also set the toughness at the optimal level and set vagueness to be greater than the minimum (i.e., $\delta^{*}$ rather than $\delta_{\min }$ in Figure 5).

The above observations are based on the assumption that toughness is also the auditor's choice and the auditor only has one client. But if toughness is not his choice or he has clients with projects requiring different amount of investments, (in other words, the optimal level can not be acquired or is uncertain) the auditor's preference regarding vagueness will be affected as the minimum attainable vagueness grows. To understand this effect, we will analyze how his preference over vagueness varies with the minimum attainable vagueness at a fixed level of toughness first, and then illustrate the investment portfolio effect on auditor's preference towards vagueness.

In response to investors' requests for tougher auditing standards in the U.S. after the massive accounting scandals of 2002, Congress authorized the PCAOB to set auditing standards. Since these regulators do not want to be blamed for any potential new accounting scandals, they tend to choose very tough auditing standards, perhaps even tougher than is optimal. In this scenario it is difficult for auditors to be seen to lobby for less tough rules. Therefore, this situation implies that the toughness of auditing standards was fixed when the PCAOB set the standards. We will therefore analyze the auditor's preference in the case where the toughness of auditing standards is an exogenous constant.

If the toughness of auditing standards is fixed at a level preferred by the auditor (the optimal level), either perfect precision or a particular level of vagueness can help him commit to this level of effort. As illustrated in Figure 5, when the vagueness $\delta$ equals zero or $\delta^{*}$, the auditor exerts the optimal level of effort $m$. However, the auditor's preference can vary with the minimum attainable vagueness. As the minimum attainable vagueness increases, the auditor will over-comply with the standards. For example, if the minimum attainable 
vagueness is indicated by $\delta_{\min }$ in Figure 5, then the auditor will choose effort equal to $m+\sqrt{3} \delta_{\min }$, which is greater than $m$. Since it is not optimal for the auditor to exert effort greater than $m$, the auditor will choose a higher level of vagueness than the minimum attainable vagueness (i.e., $\delta^{*}>\delta_{\min }$ ) in order to reduce the equilibrium level of effort to $m$. In this case, the auditor strictly prefers vaguer auditing standards.

If the toughness is too low, the auditor may prefer standards vaguer than perfect precision or minimum attainable vagueness, since vagueness allows him to commit to a higher level of effort, because his wealth is at risk. Suppose $s_{1}$ is the optimal level of effort. Figure 5 shows that the vagueness $\delta_{s 1}$ that induces $s_{1}$ is larger than the minimum attainable vagueness $\delta_{\min }$.

If, on the other hand, the toughness is too high, the auditor may prefer vaguer standards in order to excise professional judgment and avoid performing unnecessary procedures so that he can commit to the optimal level of effort. Suppose $s_{2}$ is the optimal level of effort. The vagueness $\delta_{s 2}$ that induces $s_{2}$ is larger than the minimum attainable vagueness $\delta_{\min }$.

When the auditor has multiple projects with different investment levels, there is not a unique level of effort that maximizes the net payoff of auditing a portfolio of clients. Or if the auditor has only client, but the client's investment project profitability is uncertain, then the optimal level of effort is not certain either. In these cases, the auditor prefers vague standards for the reasons shown above. To sum up, when the standards can not be set at an optimal level, the auditor prefers vague standards.

Proposition 3 summarizes the arguments. The proof of this proposition can be found in the Appendix.

\section{Proposition 3.}

a. The auditor weakly prefers precise auditing standards if he can set the toughness at the optimal level.

b. If the toughness is fixed at a non-optimal level and below $m^{\dagger}$ or can not be set at an optimal level, in other words, optimal toughness can not be acquired, then the auditor 
will choose auditing standards vaguer than the standards with minimum attainable vagueness.

Recall $m^{\dagger}$ is the minimum value of $m$ such that the auditor will choose non-compliance effort $a_{s}$. The standards should not be extremely tough because the auditor will simply not comply with them. In summary, the auditor will choose a certain toughness and vagueness strategically to commit to an optimal level of effort. In general, when the toughness is fixed at a non-optimal level or can not be set at an optimal level, the auditor will choose a higher vagueness than the minimum attainable level. When the auditor can set the toughness at the optimal level, then the auditor weakly prefers to set auditing standards precisely. Note that in reality, an auditor usually has multiple clients with different investment projects, there is no unique optimal level of toughness and the auditor therefore prefers vague standards. This explains why auditing standards have been vague long before the PCAOB came into existence.

\section{The Effect of Wealth on the Preference Regarding Vagueness}

When the auditing standards are perfectly precise, we find that small auditors will prefer the standards to be less tough than the levels preferred by large auditors, because their net payoff is larger if they can credibly commit to a higher level of effort than the noncompliance effort. Due to their limited wealth, small auditors cannot commit to as high a level of effort as large auditors. This section analyzes how auditors with different wealth will choose the properties of auditing standards when the standards are uncertain. The conventional conjecture is that smaller auditors prefer less tough and vaguer auditing standards, compared to large auditors. We show, however, that this situation is more complex than it appears.

The level of effort to which an auditor can commit varies with his wealth. Auditors can be classified into three categories based on their wealth: $W \geq I$ (large auditors), $\frac{1-\sqrt{1-(1-\beta)^{2} I^{2} / c^{2}}}{(1-\beta) / c} \leq W<I$ (medium auditors), and $W<\frac{1-\sqrt{1-(1-\beta)^{2} I^{2} / c^{2}}}{(1-\beta) / c}$ (small auditors). Recall that $\bar{s}=\sqrt{\frac{2}{c}(1-\beta) \min [W, I]-\frac{(1-\beta)^{2}(\min [W, I])^{2}}{c^{2}}}$ is the highest standard with which 
an auditor complies. Since $\bar{s}$ varies with auditor wealth, we denote the highest standard complied by small auditors by $\bar{s}_{s}$, which is smaller than the highest standard complied by medium and large auditors $\left(\bar{s}_{m}\right.$ and $\left.\bar{s}_{b}\right){ }^{21}$ Since the optimal level of effort $(1-\beta) I / c$ is less than or equal to $\bar{s}_{m}$ or $\bar{s}_{b}$, both medium and large auditors can commit to this optimal level of effort. But the cutoff points of the vagueness $\delta$ in the auditor's reaction function differ between these two groups of auditors. For the third group, the optimal level of effort $(1-\beta) I / c$ is greater than $\bar{s}_{s}$, so they can not credibly commit to $(1-\beta) I / c$. However, this group of auditors can credibly commit to $\bar{s}_{s}$, which is less than the optimal level of effort, but greater than the minimum level of effort (or noncompliance effort): $a_{s}=(1-\beta) W / c$.

The effort reaction function with respect to $\delta$ of auditors with different wealth shows that if the auditors can choose the toughness of auditing standards as well as the vagueness, then auditors with different wealth will all choose precise auditing standards, but the smallest auditors will choose less tough rules than the medium and largest auditors.

It is also likely that the largest auditor will choose the vaguest auditing standards, and the small auditors will select the least vague auditing standards. Because of their small wealth, small auditors cannot credibly commit to a level of effort higher than the noncompliance effort when the vagueness of auditing standards becomes larger. Larger auditors can commit to a high level of effort even with high vagueness. They enjoy a competitive advantage when auditing standards are vaguer, since they can commit to a higher level of effort than smaller auditors.

\subsection{INVESTORS' PREFERENCE}

If there is only one auditor, the investors weakly prefer to set the auditing standards precisely and set the toughness equal to either the first-best level $\left(\frac{(1-\beta) I}{c}\right)$ or highest committable level $(\bar{s})$ depending on the auditor wealth. Specifically, if the auditor's wealth is below the cutoff

\footnotetext{
${ }^{21} \bar{s}_{s}=\sqrt{\frac{2}{c}(1-\beta) W_{s}-\frac{(1-\beta)^{2} W_{s}^{2}}{c^{2}}}, \bar{s}_{m}=\sqrt{\frac{2}{c}(1-\beta) W_{m}-\frac{(1-\beta)^{2} W_{m}^{2}}{c^{2}}}$, and $\bar{s}_{b}=\sqrt{\frac{2}{c}(1-\beta) I-\frac{(1-\beta)^{2} I^{2}}{c^{2}}}$, where $W_{s}$ is the wealth of small auditors, $W_{m}$ is the wealth of medium auditors. Only $\bar{s}_{b}$ is fixed for all large auditors, while $\bar{s}_{s}$ and $\bar{s}_{m}$ vary with auditors' wealth.
} 
point (i.e., $\frac{1-\sqrt{1-(1-\beta)^{2} I^{2} / c^{2}}}{(1-\beta) / c}$, then the investors will set the toughness and vagueness to induce $\bar{s}$, which is the same as what would be set by the auditor; if the auditor wealth is above the cutoff point, then the investors will set the toughness and vagueness to induce $(1-\beta) I / c$, which is also the same as what would be set by the auditor. Since the auditing standards are inherently vague, there is minimum attainable vagueness the standard-setters can choose. Under this constraint, the investors essentially will choose the same level of toughness and vagueness to induce the desired level of audit effort as the auditor would, because the wealth-maximizing level of effort is the same under equilibrium regardless of bargaining power.

\subsection{MULTIPLE AUDITORS WITH HETEROGENEOUS WEALTH AND MUL- TIPLE PROJECTS WITH DIFFERENT INVESTMENTS}

If there are many auditors with different levels of wealth, the investors weakly prefer to set the

standards precisely with toughness $s=\frac{(1-\beta) I}{c}$ and hire an auditor with greater wealth. Note that this result does not mean that only large auditors can obtain auditing engagements.

Since the amount of investment $I$ would vary in reality, this model only suggests that investors with different investment opportunities would choose an auditor with the corresponding wealth. The variation of investments causes investors to set standards contingent on different investment levels. If those investment levels are known, investors can write precise contingent standards. If there are infinite investments, then the investors demand vagueness in the standards because the standards cannot be set optimally for each set of investors. In terms of auditors' preferences for auditing standards, the variation of investment affects the cutoff point, the numeric number of first-best level of effort etc., but our basic results remain the same. In reality, auditors have heterogeneous wealth and have a portfolio of clients with different investments. The optimal level of effort is not certain for the auditor and auditors with different wealth would have heterogeneous optimal level of effort as well. 
Therefore, in equilibrium, vague auditing standards are preferred.

In summary, we find that in a perfect world where the auditing standards could be set precisely and assuming homogeneous auditors and investments, both the auditor and the investors weakly prefer precise auditing standards. Moreover, if the toughness of auditing standards is fixed at a non-optimal level, then both investors and auditors prefer vaguer standards than the standards with minimum attainable vagueness. ${ }^{22}$ Since auditing standards are influenced by different parties and the standards can never be precisely optimal for every party, auditing standards with vagueness are preferred.

\subsection{UNCERTAIN RESPONSE TO VAGUE STANDARDS}

Recall that our key assumptions in the main analysis are one auditor (an aggregation of many auditors with the same wealth) and one investment project. To allow non-perfectly predictable auditor response to vague standards, we assume that the auditor would obtain a private signal $\epsilon_{i}$ regarding the standard after evaluating the client if the standards are vague. The common prior belief regarding the standards is $s \sim N\left(m, \delta^{2}\right)$. The private signal $\epsilon_{i}$ follows normal distribution with mean zero and variance $\delta_{i}^{2}$ (i.e., $\epsilon_{i} \sim N\left(0, \delta_{i}^{2}\right)$ ). The standard $s$ and private signal $\epsilon_{i}$ are jointly normally distributed. Denote the covariance of $s$ and $\epsilon_{i}$ by $\delta_{s i}$. Simple calculation shows the mean of posterior belief about the standards, denoted by $\widetilde{s}$, follows a normal distribution with mean $\widetilde{m}=m+\frac{\delta_{s i} \epsilon_{i}}{\delta_{i}^{2}}$ and variance $\widetilde{\delta^{2}}=\delta^{2}-\frac{\delta_{s i}^{2}}{\delta_{i}^{2}}$, that is

$$
\widetilde{s}=s \mid \epsilon_{i} \sim N\left(m+\frac{\delta_{s i} \epsilon_{i}}{\delta_{i}^{2}}, \delta^{2}-\frac{\delta_{s i}^{2}}{\delta_{i}^{2}}\right) .
$$

The private signal is unknown to the investors, therefore, the posterior belief regarding the standards are uncertain and the auditor effort is not perfectly predictable to the investors. Under this scenario, our key results (The auditor weakly prefers precise auditing standards

\footnotetext{
${ }^{22}$ If an auditor is risk averse and is able to choose both toughness and vagueness, then he would still prefer precise standards to avoid any risks. When toughness is too high, risk aversion will mitigate but not eliminate his preference for vagueness. When toughness is too low, risk aversion may increase his preference for vagueness to commit to a higher level of effort.
} 
if he can set the toughness at the optimal level. If the toughness can not be set optimally, then he will prefer vague standards. Investors generally have the same preferences as the auditor.) still hold with a minor modification: the auditor and investors would prefer rather than weakly prefer precise standards if they can set the toughness at the optimal level, since the non-perfectly predictable audit effort due to vagueness of the standards generates extra costs to them. Moreover, the posterior belief $\widetilde{s} \sim N\left(\widetilde{m}, \widetilde{\delta^{2}}\right)$ can be used to conjecture auditor's effort even if his effort is not perfectly predictable. There will be three effort choices: noncompliance effort (probability of compliance equals zero $P(a)=0$ ), full-compliance effort $(P(a)=1)$, and compliance effort with positive probability $(0<P(a)<1)$. The impact of vagueness on effort choices remain the same: auditor's effort increases and then decreases as the vagueness increases. Note that the probability of compliance given an audit effort $a$ is obtained from an erf function $\frac{1}{2}\left[1+\operatorname{erf}\left(\frac{a-\widetilde{m}}{\sqrt{2} \tilde{\delta}}\right)\right]$, which results in a non-closed-form solution. In order to illustrate auditor's effort increases and then decreases as the vagueness increases under normal distribution assumption, we use Figure 6. It shows the CDF of a normal distribution and the CDF of another distribution with the same mean and different variance. The distribution indicated by a dotted line has a greater variance than the one by a solid line.

If the effort chosen by the auditor is greater than the mean, then a distribution with a greater variance will cause a lower probability of compliance than a distribution with less variance. A lower probability of compliance induces the auditor to work harder. Hence, in this case, auditor effort will increase as the vagueness increases. This is consistent with the increasing section of the auditor's reaction function over vagueness. If the audit effort is less than the mean, then a distribution with less variance will cause a lower probability of compliance than one with greater variance. More precise auditing standards lead to a larger audit effort in this case. This result is consistent with the decreasing section of the auditor's reaction function over vagueness. The audit effort choice is a result of minimizing total audit cost. The auditor considers the trade-off between audit resource costs and auditor 
liability to choose the effort. Overall, this figure shows the existence of both increasing and decreasing effect of vagueness on audit effort for normal distributions. Because of this impact of vagueness on audit effort, the explanation of Figure 5 applies here and therefore we obtain the result that the auditor and investors will prefer vague standards if the toughness can not be set optimally.

To summarize, the uncertain response to vague standards can make the model more realistic but it does not affect our key results and our results are not sensitive to a different distribution assumption. We also consider alternative cases such as new functional form assumptions, or compliance with auditing standards is not sufficient to protect the auditor from liability, and the variation of strictness of legal liability regimes, and our results remain robust.

\section{Conclusion}

In U.S. accounting history, whenever massive accounting scandals have occurred, auditing standards become a target of public criticism. The most recent accounting scandals (e.g., Enron, WorldCom, Sunbeam, AOL, in 2002) led to the introduction of the Sarbanes-Oxley Act of 2002, the establishment of PCAOB auditing standards, and substantial debate over the standards. Moreover, auditing standards evolve over time and vary across countries. This paper provides an analytic framework for determining how standard setters choose the toughness and vagueness of auditing standards.

The model predicts that both the auditors and the investors prefer precise auditing standards if the standards can be set at the optimal level. However, if the toughness can not be set optimally (either too high or too low, which is usually true in reality because of heterogeneous projects and auditor wealth), then both of auditors and investors prefer vague auditing standards. When we consider the wealth effect, we find small audit firms prefer less tough rules than large audit firms because of their wealth constraint. Since auditing standards are influenced by different parties, the toughness set by the standard setting 
board would be a compromise among different parties, and cannot be optimal for every party. Therefore, this result is consistent with the world-wide trend of setting auditing standards that require more professional judgment. In addition, we find that investors generally have the same preference for the properties as auditors, which is consistent with the fact that auditing standards are mostly set by professional organizations for auditors, perhaps with input from other interested parties. This implies that investors will not necessarily be better off if they can set auditing standards directly.

This paper's findings are limited by a set of assumptions (e.g., observable auditor wealth, no litigation cost, etc.). Despite these limitations, this research sheds light on different economic agents' incentives in influencing the auditing standards-setting process, and, we believe, captures the fundamental economic elements of this process. 


\section{References}

Breuer, W. 1999. Auditor liability and the precison of auditing standards comment. Journal of Institutional and Theoretical Economics 155 (1): 207-213.

Calfee, J. E., and R. Craswell. 1984. Some effects of uncertainty on compliance with legal standards. Virginia Law Review 70 (5): 965-1003.

Caplan, D., and M. Kirschenheiter. 2004. A model of auditing under bright-line accounting standards. Journal of Accounting, Auditing and Finance 19 (4): 523-559.

Dye, R. A. 2002. Classification manipulation and nash accounting standards. Journal of Accounting Research 40 (4): 1125-1162.

Dye, R. A. 1993. Auditing standards, legal liability, and auditor wealth. Journal of Political Economy 101 (5): 887-914.

Dye, R. A. 1995. Incorporation and the audit market. Journal of Accounting and Economics 19 (1): 75-114.

Dye, R. A., and S. Sridhar. 2008. A positive theory of flexibility in accounting standards. Journal of Accounting and Economics 46 (2-3): 312-333.

Ewert, R. 1999. Auditor liability and the precision of auditing standards. Journal of Institutional and Theoretical Economics 155 (1): 181-206.

Kolstad, C. C., T. S. Ulen, and G. V. Johnson. 1990. Ex post liability for harm vs. ex ante safety regulation: Substitutes or complements? The American Economic Review 80 (4): 888-901.

Laux, V., and P. Newman. 2009. Auditor liability and client acceptance decisions. The Accounting Review forthcoming. 
Lo, K. 2007. Is the devil in the details? Business Network (BNET.com) Copyright: Institute of Chartered Accountants of British Columbia. URL http://findarticles. com/p/articles/mi_qa3984/is_200711/ai_n21137825.

Melumad, N. D., and L. Thoman. 1990. On auditors and the courts in an adverse selection setting. Journal of Accounting Research 28 (Spring): 77-120.

Narayanan, V. G. 1994. An analysis of auditor liability rules. Journal of Accounting Research 32 (Supplement): 39-59.

Nelson, J., J. Ronen, and L. White. 1988. Legal liabilities and the market for auditing services. Journal of Accounting, Auditing and Finance 3 (Summer): 255-295.

Nelson, M. W. 2003. Behavioral evidence on the effects of principles- and rules-based standards. Accounting Horizons 17 (1): 91-104.

Newman, P., E. Patterson, and R. Smith. 2005. The role of auditing in investor protection. The Accounting Review 80 (1): 289-313.

Patterson, E. R., and R. Smith. 2003. Materiality uncertainty and earnings misstatement. The Accounting Review 78 (3): 819-846.

Schipper, K. 2003. Principle-based accounting standards. Accounting Horizons 17 (1): $61-72$.

Schwartz, R. 1998. Auditors' liability, vague due care, and auditing standards. Review of Quantitative Finance and Accounting 11 (2): 183-207.

Vincent, L., L. A. Maines, E. Bartov, P. Fairfield, D. E. Hirst, T. E. Iannaconi, R. Mallett, C. M. Schrand, and D. J. Skinner. 2003. Evaluating concepts-based vs. rules-based approaches to standard setting. Accounting Horizons 17 (1): 73-89. 
Willekens, M., and D. Simunic. 2007. Precision in auditing standards: Effects on auditor and director liability and the supply and demand for audit services. Accounting and Business Research 37 (3): 217-232.

Willekens, M., A. Steele, and D. Miltz. 1996. Audit standards and auditor liability: A theoretical model. Accounting and Business Research 26 (Summer): 249-264.

Zhang, P. 2007. The impact of the public's expectations of auditors on audit quality and auditing standards compliance. Contemporary Accounting Research 24 (2): 631-654. 


\section{Appendices}

\section{Proofs}

\section{Proof of Lemma 1}

We assume the standard $s$ follows a uniform distribution with mean $m$ and variance $\delta^{2}$. Hence, the probability of compliance equals zero if the audit effort is less than $s_{l}=m-\sqrt{3} \delta$, and one if the auditor exerts effort greater than or equal to $s_{h}=m+\sqrt{3} \delta$, and equals $\frac{1}{2}\left(\frac{a-m}{\sqrt{3} \delta}+1\right)$ within the bound. The vagueness of auditing standards is represented by the variance of the distribution $\delta^{2}$ (or the standard deviation $\delta$ ), and the toughness of auditing standards is indicated by $m$, the mean of the distribution.

The auditor will choose a level of effort $a$ to minimize his total cost, which is:

$$
\begin{cases}\frac{1}{2} c a^{2}+(1-\beta)(1-a) \min [W, I] & \text { if } 0 \leq a<m-\sqrt{3} \delta \\ \frac{1}{2} c a^{2}+(1-\beta)(1-a)\left[\frac{1}{2}-\frac{1}{2} \frac{a-m}{\sqrt{3} \delta}\right] \min [W, I] & \text { if } m-\sqrt{3} \delta \leq a<m+\sqrt{3} \delta \\ \frac{1}{2} c a^{2} & \text { if } m+\sqrt{3} \delta \leq a \leq 1\end{cases}
$$

where:

(1) indicates definite liability if audit failure occurs

(2) indicates liability with positive probability

(3) indicates no liability

We obtain the optimal effort within each range as follows. Within the range of $[0, m-$ $\sqrt{3} \delta)$, the auditor's problem is similar to his problem in a strict liability regime. The auditor will, therefore, exert $a=a_{s}=\frac{(1-\beta) \min [W, I]}{c}$, which is the level exerted in a strict liability regime.

The auditor will never exert effort greater than $m+\sqrt{3} \delta$ because the auditor's expected liability is zero as long as $a=m+\sqrt{3} \delta$, and his resource cost is increasing in $a$.

$$
\text { If } m-\sqrt{3} \delta \leq a<m+\sqrt{3} \delta \text {, then } T C(a)=\frac{1}{2} c a^{2}+(1-\beta)(1-a)\left[1-\frac{1}{2}\left(\frac{a-m}{\sqrt{3} \delta}+1\right)\right] \min [W, I] \text {. }
$$

The first order condition with respect to $a$ implies

$$
a_{v}=\frac{(1-\beta) \min [W, I](1+\sqrt{3} \delta+m)}{2 \sqrt{3} \delta c+2(1-\beta) \min [W, I]} .
$$


Note that

$$
\frac{d a_{v}}{d \delta}=\frac{2 \sqrt{3} c(1-\beta) \min [W, I]\left(\frac{(1-\beta) \min [W, I]}{c}-1-m\right)}{(2 \sqrt{3} \delta c+2(1-\beta) \min [W, I])^{2}}<0 .
$$

The strict inequality is derived as following. An effort level $a \in[0,1]$ implies $\frac{(1-\beta) \min [W, I]}{c}-$ $1=a_{s}-1 \leq 0$, so $\frac{(1-\beta) \min [W, I]}{c}-1-m<0$. Both $2 \sqrt{3} c(1-\beta) \min [W, I]$ and $(2 \sqrt{3} \delta c+$ $2(1-\beta) \min [W, I])^{2}$ are greater than zero. Therefore, $\frac{d a_{v}}{d \delta}<0$, that is, the level of effort $a_{v}$ decreases with the vagueness $\delta$.

The auditor's total cost evaluated at the (conditional) optimum within each range is:

$$
\begin{cases}\frac{1}{2} c a_{s}^{2}+\left(1-a_{s}\right)(1-\beta) \min [W, I] & \text { if } 0 \leq a<m-\sqrt{3} \delta, \\ \frac{1}{2} c a_{v}^{2}+\frac{1}{2}\left(1-\frac{a_{v}-m}{\sqrt{3} \delta}\right)\left(1-a_{v}\right)(1-\beta) \min [W, I] & \text { if } m-\sqrt{3} \delta \leq a<m+\sqrt{3} \delta \\ \frac{1}{2} c(m+\sqrt{3} \delta)^{2} & \text { if } m+\sqrt{3} \delta \leq a \leq 1 .\end{cases}
$$

Denote $\min [W, I]$ to be $M$. Substituting the conditional optimal effort into the cost function and simplifying the function, we obtain the total cost evaluated at each conditional optimum:

$$
\begin{aligned}
T C\left(a_{s}\right) & =(1-\beta) M-\frac{(1-\beta)^{2} M^{2}}{2 c} \\
T C\left(a_{v}\right) & =\frac{(1-\beta) M\left[4 \sqrt{3} c \delta(m+\sqrt{3} \delta)-(1-\beta) M(1-m-\sqrt{3} \delta)^{2}\right]}{8 \sqrt{3} \delta[\sqrt{3} \delta c+(1-\beta) M]} \\
T C(m+\sqrt{3} \delta) & =\frac{1}{2} c(m+\sqrt{3} \delta)^{2},
\end{aligned}
$$

where $a_{s}=\frac{(1-\beta) \min [W, I]}{c}$, and $a_{v}=\frac{(1-\beta) \min [W, I](1+\sqrt{3} \delta+m)}{2 \sqrt{3} \delta c+2(1-\beta) \min [W, I]}$.

To determine the second-best level of audit effort given vague auditing standards that distribute uniformly under a negligence-based liability regime, we need to determine which of the costs is the lowest. The auditor will choose the conditional optimal level of effort when he achieves the lowest cost by exerting that level of effort.

$$
a^{\dagger}= \begin{cases}m+\sqrt{3} \delta & \text { if } T C(m+\sqrt{3} \delta) \leq T C\left(a_{s}\right) \text { and } T C(m+\sqrt{3} \delta) \leq T C\left(a_{v}\right), \\ a_{v} & \text { if } T C\left(a_{v}\right) \leq T C\left(a_{s}\right) \text { and } T C\left(a_{v}\right) \leq T C(m+\sqrt{3} \delta), \\ a_{s} & \text { if } T C\left(a_{s}\right) \leq T C(m+\sqrt{3} \delta) \text { and } T C\left(a_{s}\right) \leq T C\left(a_{v}\right) .\end{cases}
$$


The audit fee equals $T C\left(a^{\dagger}\right)$ and investors' payoff is $(1-\beta) a^{\dagger} I-\frac{1}{2} c a^{\dagger 2}$.

To determine the particular regions of $\delta$ where the auditor will choose one of the three conditional optimal effort choices, we compare the three total costs $T C(m+\sqrt{3} \delta), T C\left(a_{v}\right)$, and $T C\left(a_{s}\right)$. The solution of the auditor's effort reaction function of the vagueness will be divided into three regions by two cutoff points. We will show how we determine those cutoff points.

First, we determine that $T C(m+\sqrt{3} \delta)$ is greater than or equal to $T C\left(a_{v}\right)$ if $a_{v}$ is in the region of $[m-\sqrt{3} \delta, m+\sqrt{3} \delta)$.

To see this, denote $(1-\beta) \min [W, I] / c$ by $a_{s}$ and $m+\sqrt{3} \delta$ by $s$.

$$
\begin{aligned}
& T C(m+\sqrt{3} \delta)-T C\left(a_{v}\right) \\
& =\frac{c}{8 \sqrt{3} \delta\left(\sqrt{3} \delta+a_{s}\right)}\left[4 \sqrt{3} \delta\left(\sqrt{3} \delta+a_{s}\right) s^{2}-4 \sqrt{3} a_{s} s \delta+a_{s}^{2}(1-s)^{2}\right] \\
& =\frac{c}{8 \sqrt{3} \delta\left(\sqrt{3} \delta+a_{s}\right)}\left[12 s^{2} \delta^{2}-4 \sqrt{3} a_{s} s(1-s) \delta+a_{s}^{2}(1-s)^{2}\right] \\
& =\frac{c}{8 \sqrt{3} \delta\left(\sqrt{3} \delta+a_{s}\right)}\left[2 \sqrt{3} s \delta-a_{s}(1-s)\right]^{2} \geq 0
\end{aligned}
$$

By the definition of $a_{v}$, it must be in the region of $[m-\sqrt{3} \delta, m+\sqrt{3} \delta)$. Therefore, $T C(m+\sqrt{3} \delta)$ is greater than or equal to $T C\left(a_{v}\right)$ if $a_{v} \in[m-\sqrt{3} \delta, m+\sqrt{3} \delta)$.

The above analysis shows that if $a_{v} \in[m-\sqrt{3} \delta, m+\sqrt{3} \delta)$, then $T C(m+\sqrt{3} \delta) \geq T C\left(a_{v}\right)$. Hence, the auditor will choose effort equal to $a_{v}$ if $a_{v}$ is less than $m+\sqrt{3} \delta$. Since the probability of compliance equals one if the level of effort is equal to or greater than $m+\sqrt{3} \delta$, the auditor will choose effort equal to $m+\sqrt{3} \delta$ in the region where $a$ is greater than $m+\sqrt{3} \delta$. Letting $a_{v}$ equal $m+\sqrt{3} \delta$, we obtain the first cutoff point of $\delta$ :

$$
\delta_{1}=\frac{1}{4 \sqrt{3}}\left[\sqrt{\left(a_{s}-2 m\right)^{2}+8 a_{s}}-\left(a_{s}+2 m\right)\right] .
$$

In the region where $\delta \in\left[0, \delta_{1}\right)$, the effort $a_{v}$ is greater than $m+\sqrt{3} \delta$. This contradicts the definition of $a_{v}$. Therefore, if $\delta$ is less than or equal to $\delta_{1}$, then $a^{\dagger}$ equals $m+\sqrt{3} \delta$. The grey (dash dot dotted) line in Figure 3 is obtained from Equation 6.

Second, comparing $T C\left(a_{v}\right)$ with $T C\left(a_{s}\right)$, we find that $T C\left(a_{v}\right)$ is less than $T C\left(a_{s}\right)$ if $\delta$ 
is less than $\delta_{2} \cdot{ }^{23}$ The blue (dashed) line in Figure 3 is drawn based on equation $\delta=\delta_{2}$. Therefore, the auditor will choose $a^{\dagger}$ equal to $a_{v}$ if $\delta$ is less than or equal to $\delta_{2}$ and greater than $\delta_{1}$. If $\delta$ is greater than or equal to $\delta_{2}$, then $T C\left(a_{s}\right)$ is less than $T C\left(a_{v}\right)$ and therefore the auditor chooses $a^{\dagger}$ equal to $a_{s}$.

Finally, let $T C(m+\sqrt{3} \delta)$ equal to $T C\left(a_{s}\right)$. The red (dash dotted) line in Figure 3 can be obtained from Equation 7:

$$
m+\sqrt{3} \delta=\sqrt{2 a_{s}-a_{s}^{2}}
$$

Hence, Figure 3 indicates that for the vast majority value of fixed $m$, the auditor's effort increases with the vagueness when the vagueness is low; as the vagueness passes the critical value $\delta_{1}$, the auditor's effort decreases with the vagueness.

\section{Proof of Proposition 1}

Under the assumption that the auditor wealth is observable to the investors, the investors know $a=s$ if $s \leq \bar{s}$ and $a=a_{s}$ if $s>\bar{s}$. They will hire the auditor as long as their expected payoff is greater than or equal to zero. The maximum fee that the auditor can set and that is acceptable for the investors is:

$$
\begin{cases}(1-\beta) s I & \text { if } s \leq \bar{s} \\ (1-\beta) a_{s} I+(1-\beta)\left(1-a_{s}\right) \min [W, I] & \text { if } s>\bar{s}\end{cases}
$$

where $a_{s}=\frac{(1-\beta) \min [W, I]}{c}$ and $\bar{s}=\sqrt{\frac{2}{c}(1-\beta) \min [W, I]-\frac{(1-\beta)^{2}(\min [W, I])^{2}}{c^{2}}}$.

The auditor's objective function can be expressed as:

$\max _{s}(1-\beta) s I-\frac{1}{2} c s^{2}$ if $s \leq \bar{s}$,

$\max _{s}(1-\beta) a_{s} I-\frac{1}{2} c a_{s}^{2}$ if $s>\bar{s}$.

The auditor's effort choice and total profit will then be:

Total Profit $=\frac{(1-\beta)^{2} I^{2}}{2 c}$ when $a^{\dagger}=s=\frac{(1-\beta) I}{c} \leq \bar{s} ;$

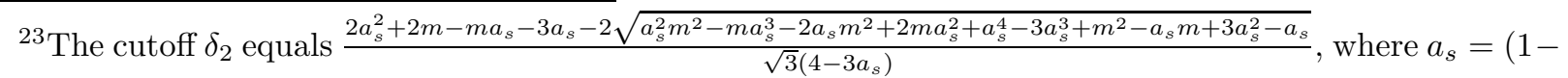
$\beta) \min [W, I] / c$. 
Total Profit $=\frac{(1-\beta)^{2} \min [W, I](2 I-\min [W, I])}{2 c}$ when $a^{\dagger}=a_{s}$ and $s>\bar{s}$.

Since the auditor wealth is observable, the condition under which the auditor will comply with the auditing standards $\frac{(1-\beta) I}{c}$ is also public knowledge. That is, if the level of auditing standards $\frac{(1-\beta) I}{c}$ is lower than or equal to $\bar{s}=\sqrt{\frac{2}{c}(1-\beta) \min [W, I]-\frac{(1-\beta)^{2}(\min [W, I])^{2}}{c^{2}}}$ which is the highest level of standards with which the auditor will comply, then it is common knowledge that the auditor will comply with the standards. The highest level of auditing standard with which the auditor will comply, $\bar{s}$, varies with the auditor wealth. Hence, whether $\frac{(1-\beta) I}{c}$ is greater than or less than $\bar{s}$ depends on the auditor's wealth.

Next, we show that auditors with more wealth will choose tougher auditing standards than auditors with less wealth. Case one: the auditor wealth is greater than or equal to the investment amount $W \geq I$. The condition under which the auditor will comply with the auditing standards is satisfied (i.e., $\left.\frac{(1-\beta) I}{c} \leq \bar{s}\right)$. The auditor will set $s=\frac{(1-\beta) I}{c}$ and exert effort equal to the standards.

Case two: the auditor wealth is less than the amount of investment $W<I$, but greater than or equal to a cutoff point $W^{*}=\frac{1-\sqrt{1-(1-\beta)^{2} I^{2} / c^{2}}}{(1-\beta) / c}$. The auditor will still comply with the standard with toughness equal to $\frac{(1-\beta) I}{c}$, because the condition $\frac{(1-\beta) I}{c} \leq \bar{s}=$ $\sqrt{\frac{2}{c}(1-\beta) \min [W, I]-\frac{(1-\beta)^{2}(\min [W, I])^{2}}{c^{2}}}$ is satisfied. Simplifying this condition, we obtain $W^{*}=\frac{1-\sqrt{1-(1-\beta)^{2} I^{2} / c^{2}}}{(1-\beta) / c}$. Hence, although his wealth is less than the amount of investment, as long as the auditor wealth is greater than a threshold $W^{*}$, the auditor will comply with the standards because he can credibly commit to the standard.

In the above two cases, the auditor's total profit is $\frac{(1-\beta)^{2} I^{2}}{2 c}$ since the auditor sets the level of standards to maximize his profit, exerting effort $a^{\dagger}=s=(1-\beta) I / c$.

If $I>W$ and $\frac{1-\beta}{2 c}>\frac{W}{I^{2}+W^{2}}$ (i.e., $W<W^{*}=\frac{1-\sqrt{1-(1-\beta)^{2} I^{2} / c^{2}}}{(1-\beta) / c}$ ), then it is too costly for the auditor to comply with $s=(1-\beta) I / c$ since $(1-\beta) I / c$ will be greater than $\bar{s}$. However, as a standard setter, the auditor can set the toughness to be lower than $(1-\beta) I / c$ and higher than $a_{s}=(1-\beta) W / c$. Suppose, for example, that the toughness $s$ equals $(1-\beta) W / c+\epsilon$, where $\epsilon$ is a small positive number and is less than $(1-\beta)(I-W) / c$. If 
$(1-\beta) W / c+\epsilon \leq \bar{s}$, then the equilibrium toughness of auditing standards will be $(1-\beta) W / c+\epsilon$ and the auditor will be able to commit to this level of effort. Since the auditor's rent increases with the level of effort if it is less than $(1-\beta) I / c$, the auditor will choose $\epsilon$ such that $(1-\beta) W / c+\epsilon=\bar{s}=\sqrt{\frac{2}{c}(1-\beta) W-\frac{(1-\beta)^{2} W^{2}}{c^{2}}}$, which increases with auditor wealth $W$.

\section{Proof of Proposition 2}

The process through which the investors choose the auditing standards is illustrated as follows. Investors anticipate that the auditor will choose $a^{\dagger}=s$ if $s \leq \bar{s}$ and choose $a^{\dagger}=a_{s}$ if $s>\bar{s}$. The investors' payoff is maximized at $a^{*}=(1-\beta) I / c$. This optimal level of effort $a^{*}$ is less than or equal to $\bar{s}$ if $I<W$ or if $I>W$ and $W \geq W^{*}=\frac{1-\sqrt{1-(1-\beta)^{2} I^{2} / c^{2}}}{(1-\beta) / c}$. It is greater than $\bar{s}$ if $W<W^{*}$. On the other hand, if the toughness is higher than $a_{s}$ but lower than $a^{*}$ (i.e., $s=(1-\beta) W / c+\epsilon$, where $\epsilon$ is a small positive number), the auditor with wealth less than $W^{*}$ will still comply with it. Thus, the auditor will exert $a=s=(1-\beta) I / c$ if $I<W$ or if $I>W$ and $W \geq W^{*}$, and exert $a=s=(1-\beta) W / c+\epsilon$ if $W<W^{*}$. The investors' payoff given $a=(1-\beta) W / c+\epsilon$ is higher than the payoff given $a=a_{s}=(1-\beta) W / c$.

Therefore, the investors will set $s=(1-\beta) I / c$ if the auditor has more wealth than $W^{*}$, and set $s=(1-\beta) W / c+\epsilon$ if the auditor has less wealth than $W^{*}$. Their corresponding payoff is $(1-\beta) s I-\frac{1}{2} c s^{2}$ where $s=(1-\beta) I / c$ or $(1-\beta) W / c+\epsilon$. Note that this result is derived under the assumption of one auditor.

As shown in the previous proof, an auditor with large wealth will set the toughness equal to the first-best level of effort, and an auditor with small wealth will set the toughness equal to the highest possible auditing standards to which his wealth allows him to commit, which is less than the first-best. Therefore, the investors have the same preference for toughness as the auditor. 


\section{Proof of Proposition 3}

The auditor will not be worst off by setting the toughness to be at the optimal level $((1-\beta) I / c$ for wealth greater than $W^{*}$ and $\left.(1-\beta) W / c+\epsilon=\bar{s}_{w}=\sqrt{\frac{2}{c}(1-\beta) W-\frac{(1-\beta)^{2} W^{2}}{c^{2}}}\right)$ and vagueness to be zero. The auditor could also set the toughness at the optimal level and set vagueness to be $\delta^{*}$. To solve for $\delta^{*}$, we start from $a_{v}=\frac{(1-\beta) \min [W, I](1+\sqrt{3} \delta+m)}{2 \sqrt{3} \delta c+2(1-\beta) \min [W, I]}$. Rearranging the terms, we will have $\delta=\frac{\frac{(1-\beta) \min [W, I]}{c}\left(1+m-2 a_{v}\right)}{\sqrt{3}\left(2 a_{v}-\frac{(1-\beta) \min [W, I}{c}\right)}$. Let $m=a_{v}=(1-\beta) I / c$ and we will get $\delta^{*}=\left(1-\frac{(1-\beta) I}{c}\right) / \sqrt{3}$. Let $m=a_{v}=\bar{s}_{w}$ and we will get $\delta^{*}=\frac{\frac{(1-\beta) W}{c}\left(1+m-2 \bar{s}_{w}\right)}{\sqrt{3}\left(2 \bar{s}_{w}-\frac{(1-\beta) W}{c}\right)}$. Therefore, the auditor weakly prefers precise auditing standards when toughness is optimal.

Recall that $m^{\dagger}$ is the minimum value of $m$ such that the auditor will choose effort equal to $a_{s}$. As shown earlier, for the vast majority of values of $m$ (e.g., $m<m^{\dagger}$ ), the auditor's effort will be $m+\sqrt{3} \delta$ and then $a_{v}$ as vagueness increases.

If the toughness is too low (i.e., $m+\epsilon=s_{1}=a_{v}$ ), where $s_{1}$ is the optimal level of effort, then the amount of vagueness that induces $a_{v}=s_{1}$ is $\delta=\frac{\frac{(1-\beta) \min [W, I]}{c}\left(1+m-2 s_{1}\right)}{\sqrt{3}\left(2 s_{1}-\frac{(1-\beta) \min [W, I]}{c}\right)}>0$, which means that the auditor prefers standards vaguer than perfect precision. The intuition is vagueness allows him to commit to a higher level of effort, because his wealth is at risk.

If the toughness is too high (i.e., $m-\epsilon=s_{2}=a_{v}$ ), where $s_{2}$ is the optimal level of effort

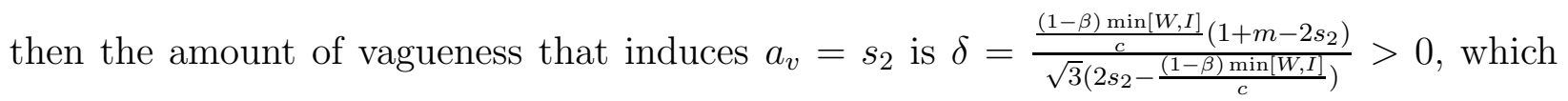
means the auditor prefers vaguer standards. The intuition is vagueness allows the auditor to excise professional judgment and avoid performing unnecessary procedures so that he can commit to the optimal level of effort.

When the auditor has multiple clients with different investments, the $I$ is not unique and therefore, the optimal level of effort is not certain. Note that if the profitability ( $\beta$ the probability of project being good) is uncertain, then the optimal level of effort is uncertain as well. When the optimal level of effort is not certain, the toughness chosen by the auditor would be either too high or too low, under which the auditor prefers vaguer standards. 


\section{Figures}

\section{Game Tree Summary}

Investor offers (or not) an audit contract $(F, a)$; auditor accepts or not*

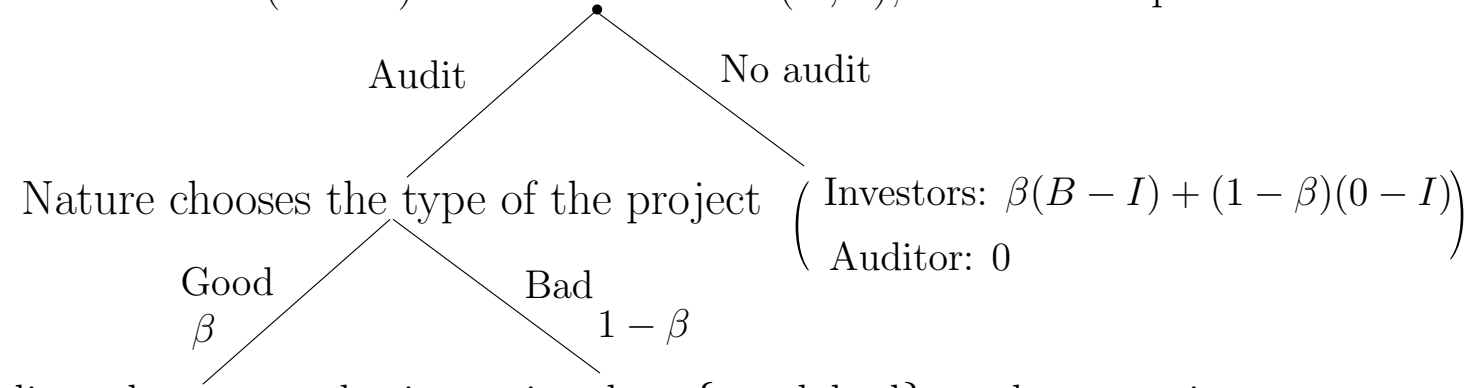

The auditor chooses $a$, obtains a signal $\in\{$ good, bad $\}$, and reports it

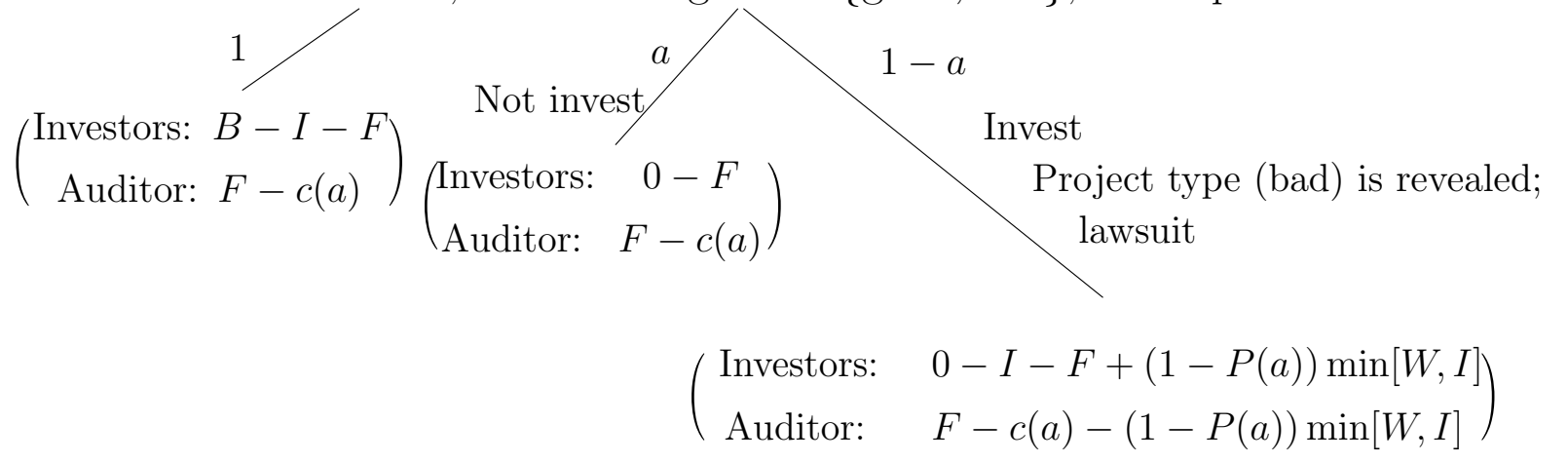

\section{Objectives}

Investors: $\quad(1-\beta) a I-F+(1-\beta)(1-a)(1-P(a)) \min [W, I]$

Auditor: $\quad F-c(a)-(1-\beta)(1-a)(1-P(a)) \min [W, I]$

In a negligence-based liability regime with due care defined by auditing standards, $P(a)$ varies with the distribution of auditing standards.

*The contract includes audit effort $a$ because it is incentive compatible for the auditor to choose this effort.

Figure 1: Game tree summary and players' objectives 


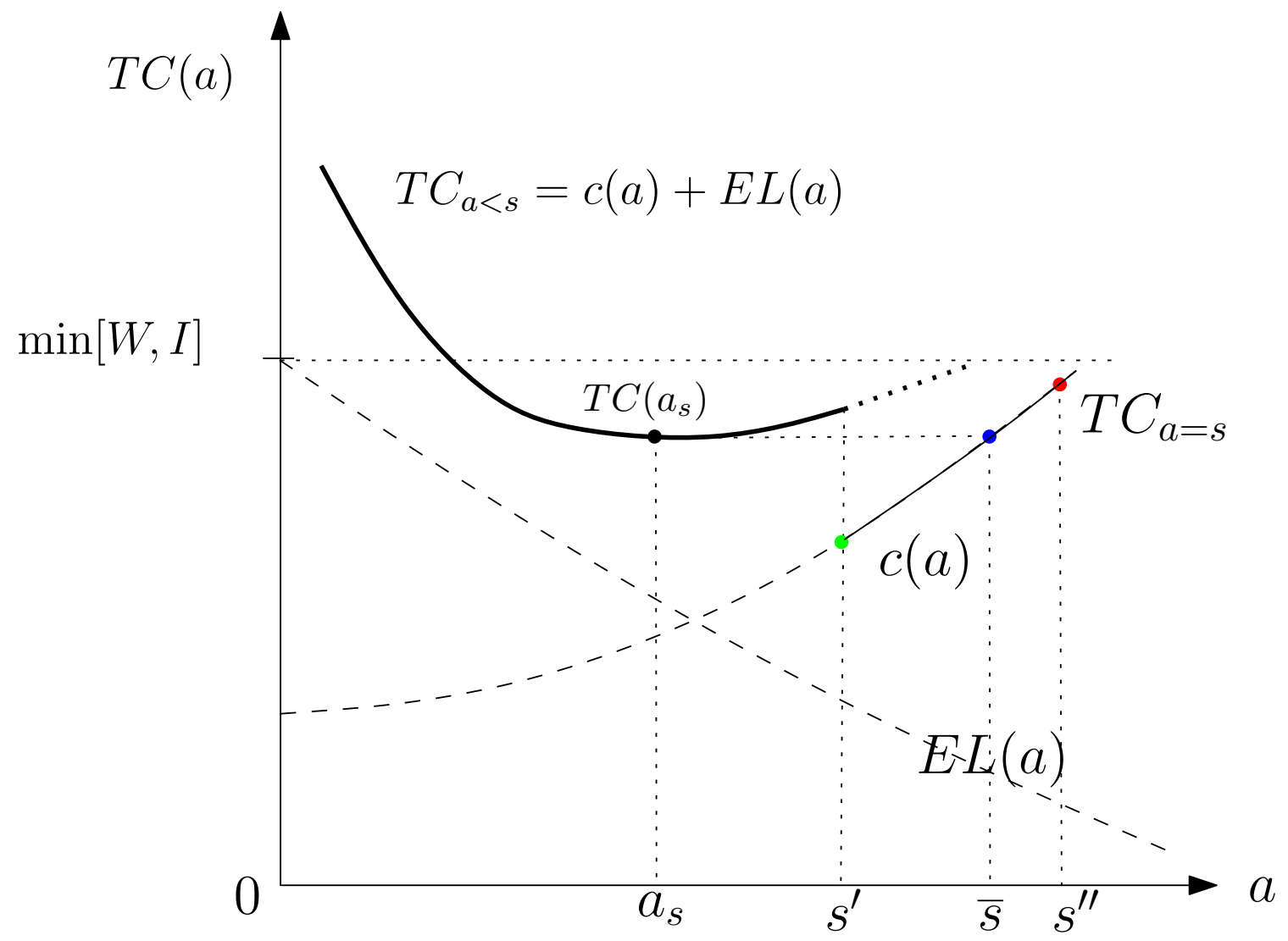

This figure illustrates auditors total cost when auditing standards are perfectly precise. When an auditor does not comply with the standards, the total cost $T C_{a<s}$ is $c(a)+E L(a)$. When the auditor complies with the standards, the total cost $T C_{a=s}$ is simply the resource cost $c(a)$.

If the effort level required by the standards, " $s$ " equals $s^{\prime}$, then the auditor's cost of complying is $c\left(s^{\prime}\right)$ which is less than $T C\left(a_{s}\right)$. Moreover, if the standard equals $s^{\prime \prime}$, then the auditor's cost of complying $c\left(s^{\prime \prime}\right)$ is greater than $T C\left(a_{s}\right)$. Therefore, the highest standard with which the audit will comply, ' $\bar{s}$,' is such that the auditor is indifferent between compliance and noncompliance (i.e., $\left.c(\bar{s})=T C\left(a_{s}\right)\right)$.

Figure 2: Auditor's total cost given precise auditing standards 


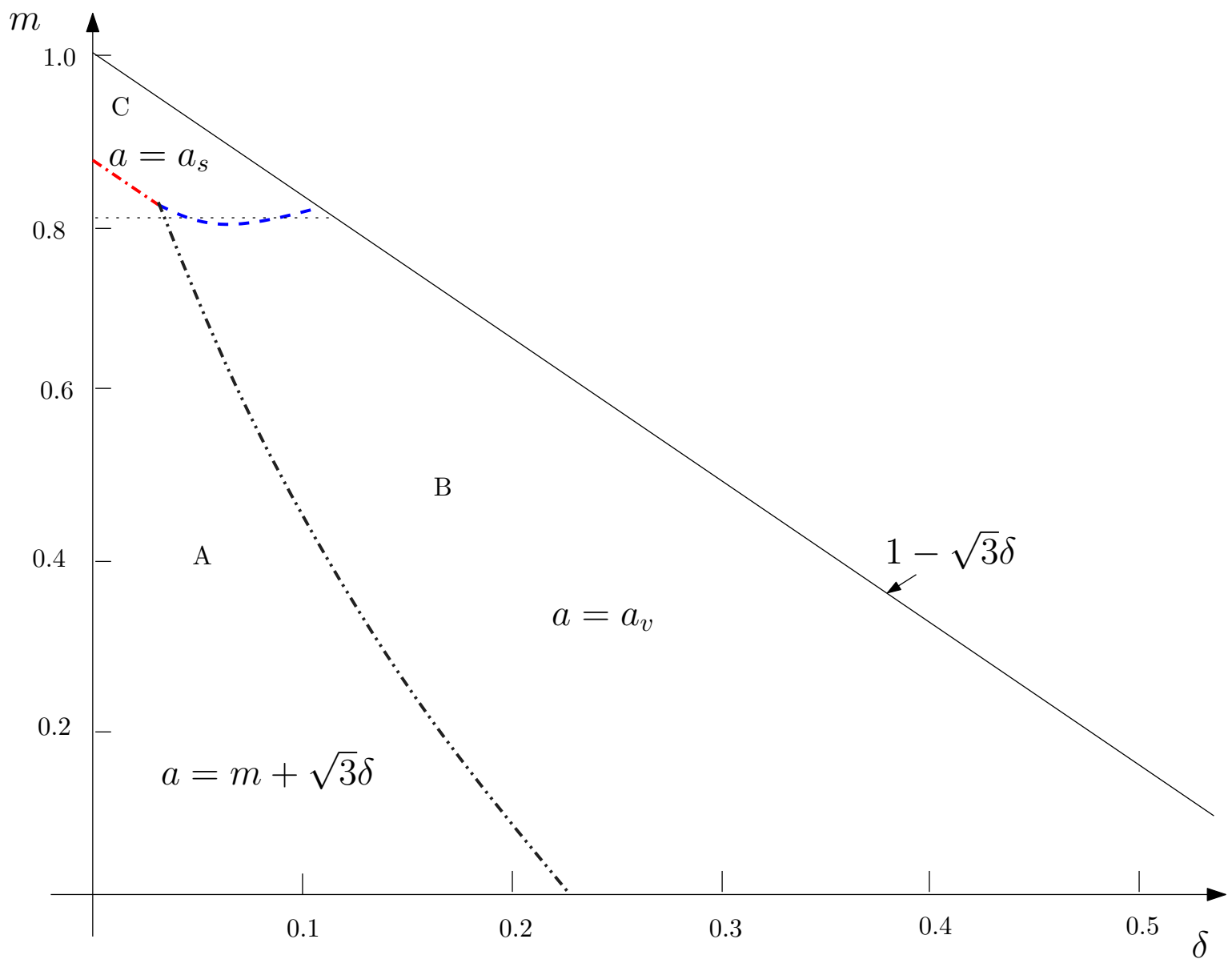

This figure illustrates the auditor's effort choice (i.e., $m+\sqrt{3} \delta$, or $a_{v}$, or $a_{s}$ ) as a function of toughness $m$ and vagueness $\delta$. Recall $m$ is the mean and $\delta$ is the variance of the distribution.

The grey (dash dot dotted) line is the indifference curve where $m+\sqrt{3} \delta$ is equal to $a_{v}$. The red line (dash dotted) provides the values of $m$ and $\delta$ for which the auditor is indifferent in choosing $m+\sqrt{3} \delta$ or $a_{s}$. At the blue (dashed) line, the auditor is indifferent between $a_{s}$ and $a_{v}$. The line indicated by $1-\sqrt{3} \delta$ is the boundary for $m$, since $m+\sqrt{3} \delta$ should be less than or equal to one. The feasible region, which is below $1-\sqrt{3} \delta$, is partitioned into three sets by the grey, red, and blue lines. When $m$ and $\delta$ fall into region A, the auditor chooses his effort equal to $m+\sqrt{3} \delta$. When the toughness and vagueness are in region $\mathrm{B}$, the auditor will choose $a_{v}$ to be his effort level. When $m$ and $\delta$ is in the upper corner, region $\mathrm{C}$, the auditor will choose $a_{s}$.

Figure 3: How auditor's effort varies with toughness and vagueness 


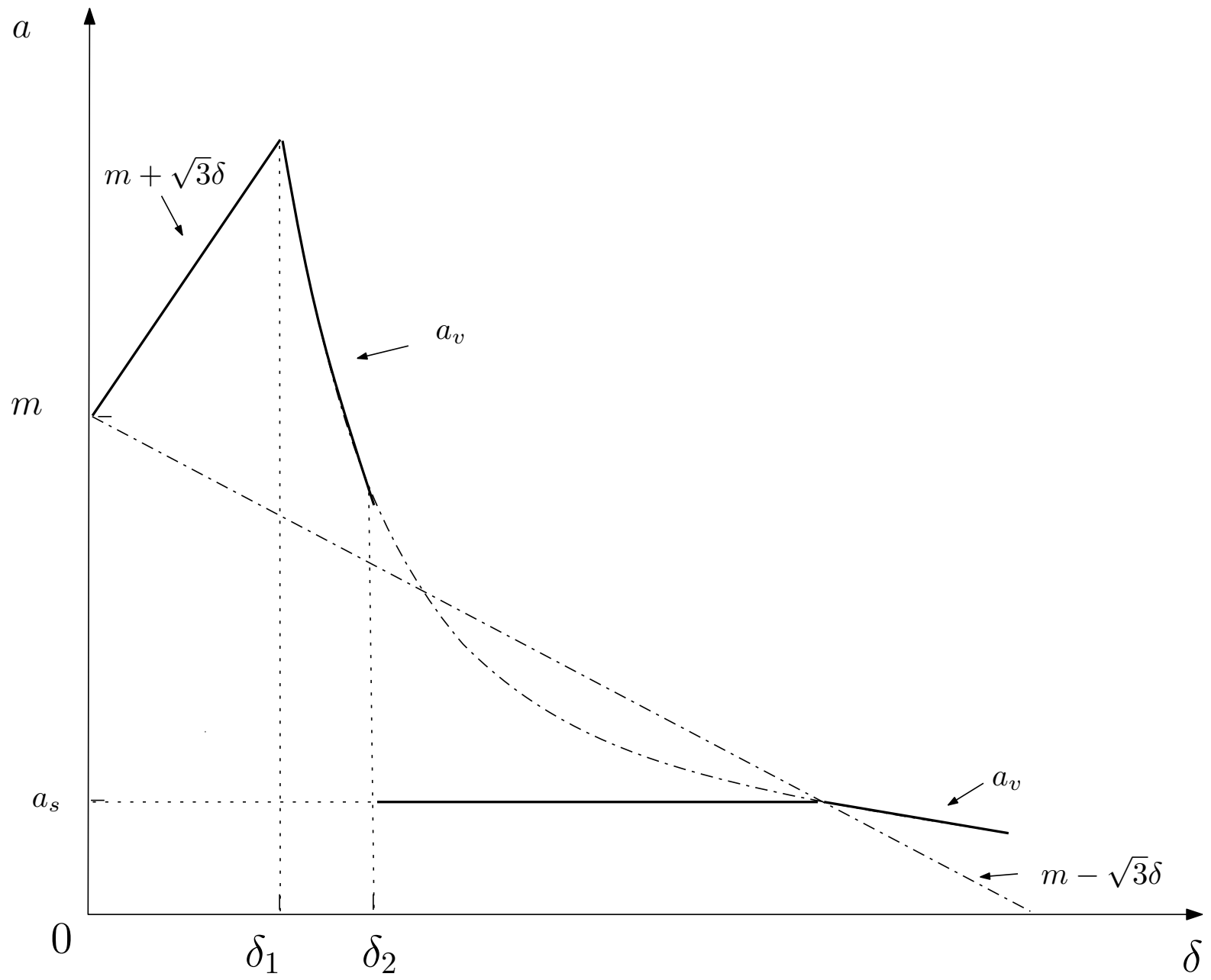

To illustrate auditor's effort reaction towards increased vagueness at a given value of $m$, we choose a particular $m$ and draw this figure illustrating the auditor's effort choice as a function of $\delta$.

Suppose $m$ is quite high as indicated by the dotted line in the previous figure. We can see that as $\delta$ increases, an auditor first chooses effort equal to $m+\sqrt{3} \delta$; then $a_{v}$; then $a_{s}$; and then $a_{v}$ once again.

As shown by solid lines in this figure, the auditor's effort will increase with the vagueness when the equilibrium level of effort is $m+\sqrt{3} \delta$, and will decrease with the vagueness if the equilibrium level of effort is $a_{v}$. If $a^{\dagger}=a_{s}$, then the vagueness of auditing standards will not affect the auditor's effort.

Note that for the vast ma ority of values of $m$, the auditor's effort will be $m+\sqrt{3} \delta$ and then $a_{v}$ as vagueness increases, suggesting that the auditor will initially increase and then decrease his effort as vagueness increases.

Figure 4: Auditor's effort level given a level of vagueness 


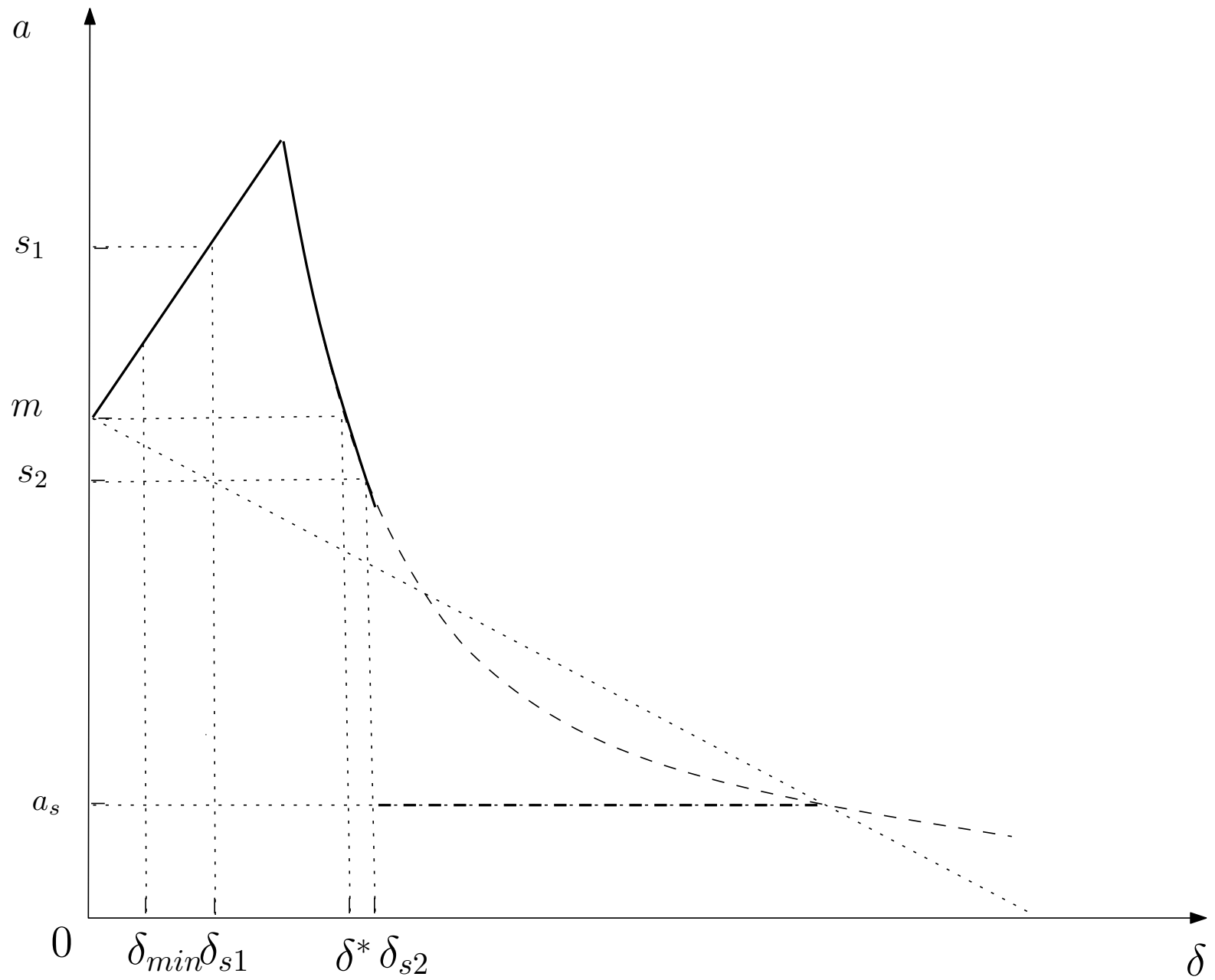

This figure illustrates an auditor's preference over vagueness given a level of toughness. If the toughness is fixed at the optimal level, either perfect precision or a particular level of vagueness can help him commit to this level of effort. As illustrated in this figure, when the vagueness $\delta$ equals zero or $\delta^{*}$, the auditor exerts the optimal level of effort $m$. If the toughness is too low, the auditor may prefer standards vaguer than perfect precision or minimum attainable vagueness $\delta_{m i n}$, since vagueness allows him to commit to a higher level of effort, because his wealth is at risk. Suppose $s_{1}$ is the optimal level of effort. This figure shows that the vagueness $\delta_{s 1}$ that induces $s_{1}$ is larger than the minimum attainable vagueness $\delta_{\min }$.

If the toughness is too high, the auditor may prefer vaguer standards in order to excise professional judgment and avoid performing unnecessary procedures so that he can commit to the optimal level of effort. Suppose $s_{2}$ is the optimal level of effort. The vagueness $\delta_{s 2}$ that induces $s_{2}$ is larger than the minimum attainable vagueness $\delta_{\min }$.

Figure 5: Preference regarding vagueness if toughness is constant 


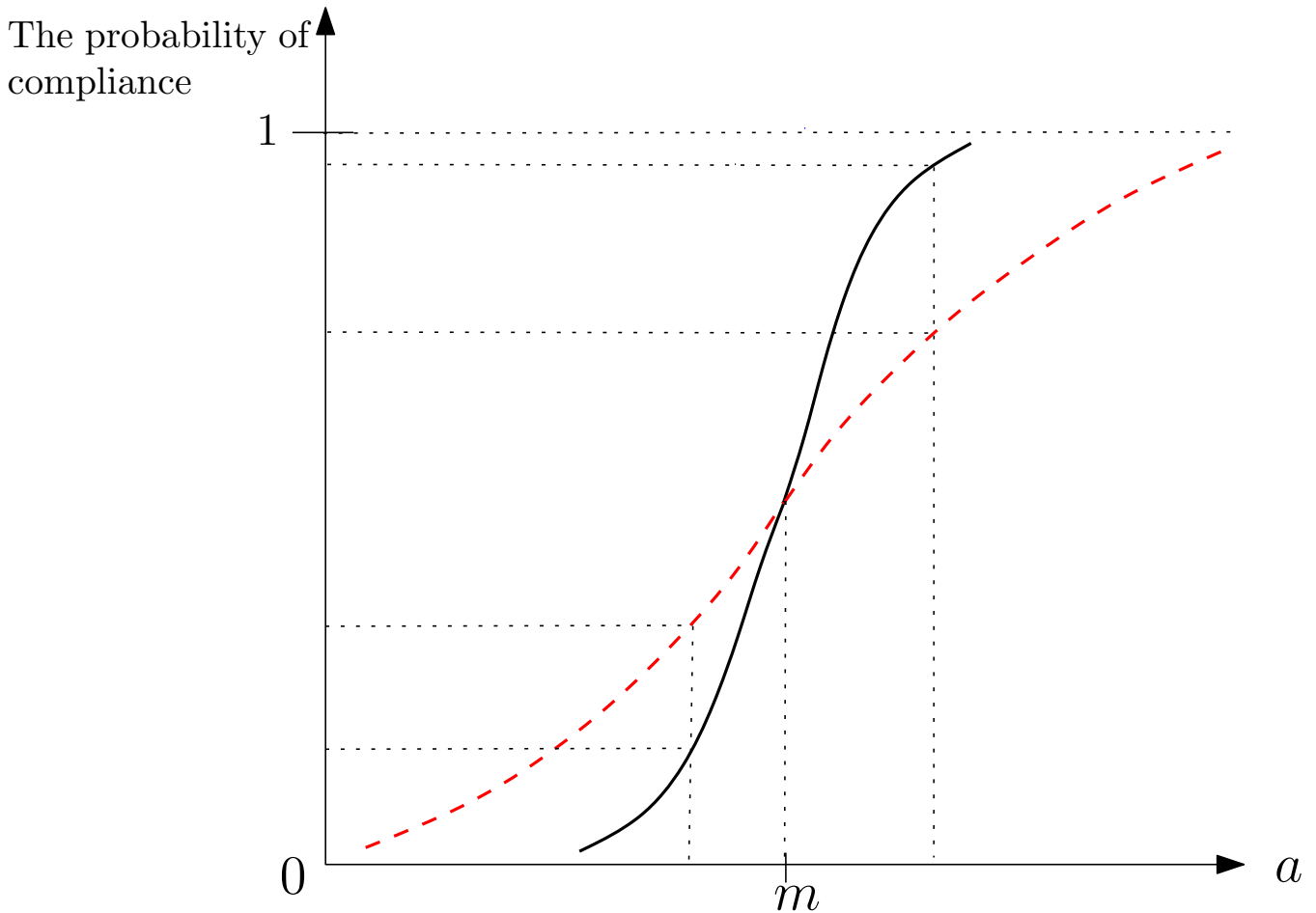

This figure illustrates the cumulative distribution function (CDF) of a normal distribution and the CDF of another normal distribution with the same mean and different variance. The distribution indicated by a dotted line has a greater variance than the one by a solid line.

If the effort chosen by the auditor is greater than the mean, then a distribution with a greater variance will cause a lower probability of compliance than a distribution with less variance. A lower probability of compliance induces the auditor to work harder. Hence, in this case, auditor effort will increase as the vagueness increases. This is consistent with the increasing section of the auditor's reaction function over vagueness. If the audit effort is less than the mean, then a distribution with less variance will cause a lower probability of compliance than one with greater variance. More precise auditing standards lead to a larger audit effort in this case. This result is consistent with the decreasing section of the auditor's reaction function over vagueness. The audit effort choice is a result of minimizing total audit cost. The auditor considers the trade-off between audit resource costs and auditor liability to choose the effort. Overall, this figure shows the existence of both increasing and decreasing effect of vagueness on audit effort for normal distributions.

Figure 6: CDFs of normal distributions with the same mean and difference variance 